Cite this: Phys. Chem. Chem. Phys., 2014, 16, 8270

Received 20th November 2013, Accepted 14th March 2014

DOI: $10.1039 / c 3 c p 54918 f$

www.rsc.org/pccp

\section{Solid state chemistry of nitrogen oxides - Part II: surface consumption of $\mathrm{NO}_{2}$}

\author{
S. Ioppolo, ${ }^{\text {ab }}$ G. Fedoseev, ${ }^{c}$ M. Minissale, ${ }^{d}$ E. Congiu, ${ }^{d}$ F. Dulieu $^{d}$ and H. Linnartz ${ }^{\star c}$
}

Nitrogen oxides are considered to be important astrochemical precursors of complex species and prebiotics. However, apart from the hydrogenation of solid NO that leads to the surface formation of hydroxylamine, little is known about the full solid state reaction network involving both nitrogen and oxygen. Our study is divided into two papers, hereby called Part I and Part II. In the accompanying paper, we investigate the surface reactions $\mathrm{NO}+\mathrm{O} / \mathrm{O}_{2} / \mathrm{O}_{3}$ and $\mathrm{NO}+\mathrm{N}$ with a focus on the formation of $\mathrm{NO}_{2}$ ice. Here, we complement this study by measurements of the surface destruction of solid $\mathrm{NO}_{2}$, e.g., $\mathrm{NO}_{2}+\mathrm{H} / \mathrm{O} / \mathrm{N}$. Experiments are performed in two separate ultra-high vacuum setups and therefore under different experimental conditions to better constrain the experimental results. Surface reaction products are monitored by means of Fourier Transform Reflection Absorption Infrared Spectroscopy (FT-RAIRS) and Temperature Programmed Desorption (TPD) techniques using mass spectrometry. The surface destruction of solid $\mathrm{NO}_{2}$ leads to the formation of a series of nitrogen oxides such as $\mathrm{NO}, \mathrm{N}_{2} \mathrm{O}$, $\mathrm{N}_{2} \mathrm{O}_{3}$, and $\mathrm{N}_{2} \mathrm{O}_{4}$ as well as $\mathrm{HNO}, \mathrm{NH}_{2} \mathrm{OH}$, and $\mathrm{H}_{2} \mathrm{O}$. When $\mathrm{NO}_{2}$ is mixed with an interstellar more relevant apolar (i.e., $\mathrm{CO}$ ) ice, solid $\mathrm{CO}_{2}$ and $\mathrm{HCOOH}$ are also formed due to interactions between different reaction routes. The astrophysical implications of the full nitrogen and oxygen reaction network derived from Parts I and II are discussed.

\section{Introduction}

Ice-covered dust grains play a key role in the chemistry of the interstellar medium. The cumulative outcome of recent observations, laboratory studies, and astrochemical models indicates that there is a strong interplay between the gas and the solid phase throughout the formation process of molecules in space. ${ }^{1,2}$ Surface reaction mechanisms on cold dust grains initiate molecular chemistry starting with the formation of $\mathrm{H}_{2}$, and dominate the formation of complex organic molecules (COMs) in space. Indeed, interstellar grains provide surfaces on which gas-phase species can accrete, meet, and react, and to which they can donate the excess energy. Therefore, in dense cold clouds, icy dust grains act both as molecular reservoirs and as sites for catalysis.

Complex grain surface chemistry is also triggered by photoninduced cosmic ray irradiation and particle bombardment, e.g.,

\footnotetext{
${ }^{a}$ Division of Geological and Planetary Sciences, California Institute of Technology, 1200 E. California Blvd., Pasadena, California 91125, USA

${ }^{b}$ Institute for Molecules and Materials, Radboud University Nijmegen, P.O. Box 9010, 6500 GL Nijmegen, The Netherlands

${ }^{c}$ Raymond and Beverly Sackler Laboratory for Astrophysics, Leiden Observatory, Leiden University, P.O. Box 9513, 2300 RA Leiden, The Netherlands. E-mail: linnartz@strw.leidenuniv.nl

${ }^{d}$ LERMA-LAMAp, Université de Cergy-Pontoise, Observatoire de Paris, ENS, UPMC, UMR 8112 du CNRS, 5 Mail Gay Lussac, 95000 Cergy Pontoise Cedex, France
}

free atoms, electrons, and cosmic rays. ${ }^{1,3}$ During later stages of star formation, condensed-phase molecules can be thermally processed to form more complex species. ${ }^{4}$ Ultimately, ices may desorb from the dust grains and participate in second generation gas-phase reaction schemes. ${ }^{5}$ Some of this material can recondense in the inner part of the protoplanetary disk, according to their snow-lines, and then be eventually delivered to icy planetesimals and planets. ${ }^{6}$

Nitrogen-containing molecules are essential for life on Earth. Therefore, understanding the nitrogen and oxygen chemistry in space is an important step to link the formation of interstellar COMs to the origin of life. However, to date, surface nitrogen chemistry has been poorly understood. Laboratory studies showed that ion irradiation of interstellar relevant ices containing $\mathrm{N}_{2}$ (e.g., $\mathrm{H}_{2} \mathrm{O}: \mathrm{N}_{2}+60 \mathrm{keV}$ of $\mathrm{Ar}^{2+}, \mathrm{CO}: \mathrm{N}_{2}+200 \mathrm{keV}$ of $\mathrm{H}^{+}$) leads to the formation of some nitrogen oxides, such as $\mathrm{NO}, \mathrm{N}_{2} \mathrm{O}$, and $\mathrm{NO}_{2}$. When carbon-bearing species are present in the ice that are irradiated with a mixture containing $\mathrm{N}_{2}, \mathrm{OCN}^{-}$is also formed. ${ }^{7,8}$ Laboratory studies of non-energetic surface processing showed that, for instance, ammonia $\left(\mathrm{NH}_{3}\right)$, hydroxylamine $\left(\mathrm{NH}_{2} \mathrm{OH}\right)$, nitrogen dioxide $\left(\mathrm{NO}_{2}\right)$, dinitrogen trioxide $\left(\mathrm{N}_{2} \mathrm{O}_{3}\right)$, nitrous acid $\left(\mathrm{HNO}_{2}\right)$, and nitric acid $\left(\mathrm{HNO}_{3}\right)$ are efficiently formed at low temperatures through hydrogenation of $\mathrm{N}$-atoms, $\mathrm{NO}+\mathrm{H}, \mathrm{NO}+$ $\mathrm{O}_{2}, \mathrm{NO}+\mathrm{NO}_{2}, \mathrm{NO}+\mathrm{OH}$, and $\mathrm{NO}_{2}+\mathrm{OH}$ reactions, respectively. ${ }^{9-16}$

In the accompanying paper, hereafter referred to as Part I, ${ }^{17}$ we investigate the oxygenation of solid $\mathrm{NO}\left(\mathrm{NO}+\mathrm{O} / \mathrm{O}_{2} / \mathrm{O}_{3}\right)$ at 
low temperature, on different substrates (silicate, graphite, compact amorphous solid water - ASW, and gold), and in different environments (pure NO, polar ice - $\mathrm{NO}: \mathrm{H}_{2} \mathrm{O}$, and apolar ice - NO:CO). Solid $\mathrm{NO}_{2}$ is shown to be efficiently formed in all cases indicating that the reaction $\mathrm{NO}+\mathrm{O}$ is barrierless or has a small barrier. Despite these findings, interstellar $\mathrm{NO}_{2}$ has not been observed yet. According to the UMIST database, $\mathrm{NO}_{2}$ has an estimated abundance of $\sim 10^{-11}$ wrt molecular hydrogen in the early stage of an interstellar cloud, and $\sim 2 \times 10^{-10}$ later at steady state. ${ }^{18}$ The non-detection of $\mathrm{NO}_{2}$ can be explained by efficient photodissociation and/or a non-energetic surface consumption pathway. The latter is the topic of the present study that shows the laboratory destruction of $\mathrm{NO}_{2}$ through surface reactions $\left(\mathrm{NO}_{2}+\mathrm{H} / \mathrm{O} / \mathrm{N}\right)$.

It should be noted that pure $\mathrm{NO}$ and $\mathrm{NO}_{2}$ ice are not expected to exist in space, however interstellar $\mathrm{NO}$ and $\mathrm{NO}_{2}$ should be present in the solid phase mixed with more abundant species. The astrophysical relevance of the work presented here aims at characterizing selected surface reaction processes, such as $\mathrm{NO}+\mathrm{H} / \mathrm{O} / \mathrm{N}$ and $\mathrm{NO}_{2}+\mathrm{H} / \mathrm{O} / \mathrm{N}$, that occur in interstellar ices and that can explain the formation of more complex species in space (e.g., $\left.\mathrm{NH}_{2} \mathrm{OH}\right)$. In order to achieve this goal, a systematic study is presented that starts from the simplest case of pure ices and also includes interstellar more relevant environments. In Part I, we studied the formation of $\mathrm{NO}_{2}$ in both polar and apolar ices. Fig. 3 of Part I shows that all the infrared features of $\mathrm{N}$-bearing species present in a water-rich ice are broadened, shifted, and overlap with the strong $\mathrm{OH}$ bending mode of water ice. Thus, the unambiguous identification of species consumed or formed in the ice upon atom exposure is not trivial in a polar environment. On the other hand, Fig. 4 of Part I shows that a CO-rich ice is a better environment to study surface reactions of $\mathrm{N}$-bearing species, because all the spectral features are sharp and do not overlap with the CO modes. Therefore, only the results for pure and interstellar relevant apolar ices are presented here.

\section{Experimental}

As for Part I, experiments are performed in two different setups: SURFRESIDE $^{2}$ at the Sackler Laboratory for Astrophysics, Leiden University, The Netherlands, and FORMOLISM at the University of Cergy-Pontoise, France. Here follows a brief description of the setups and the experimental methods, since both systems are discussed in detail elsewhere. ${ }^{12,15}$ The use of two ultra-high vacuum (UHV) systems allows for complementary studies of selected interstellar relevant surface reactions. Therefore, a combination of experiments performed in these setups gives information on surface reactions occurring at different surface coverages (sub-monolayer $v s$. multilayer regime), on different substrates (gold, silicates, graphite, and ASW ice), and in different matrix environments (pure NO and $\mathrm{NO}_{2}, \mathrm{NO}$ in polar ice, and $\mathrm{NO}$ and $\mathrm{NO}_{2}$ in apolar ice).

\subsection{SURFRESIDE ${ }^{2}$ setup}

SURFRESIDE $^{2}$ consists of three distinct UHV chambers. In the main chamber, ices are deposited with monolayer precision (where $1 \mathrm{ML}$ is assumed to be $10^{15}$ molecules $\mathrm{cm}^{-2}$ ) and processed at astronomically relevant temperatures (13-300 K) on a gold substrate. Reflection Absorption Infrared Spectroscopy (RAIRS) and Temperature Programmed Desorption (TPD) are used as analytical tools to characterize the ice composition. In the other chambers different atom sources are mounted for the controlled production of well characterized atom (molecular) beams. Two different atom sources are used, one Hydrogen Atom Beam Source (HABS, Dr Eberl MBE-Komponenten GmbH) ${ }^{19-21}$ based on thermal cracking, and a Microwave Atom Source (MWAS, Oxford Scientific Ltd) ${ }^{22,23}$ that implements a microwave discharge ( $300 \mathrm{~W}$ at $2.50 \mathrm{GHz}$ ). The HABS is used to hydrogenate/ deuterate the sample, while the MWAS can produce beams of different atoms and radicals (e.g., $\mathrm{H}, \mathrm{D}, \mathrm{O}, \mathrm{OH}, \mathrm{OD}$, and $\mathrm{N}$ ).

The two custom-made atom line chambers present identical geometrical characteristics. Shutters separate the beam lines from the main chamber and allow for an independent operation of the individual atom beam lines. A quartz pipe is placed after each shutter and along the path of the dissociated beam. The nose-shaped form of the pipe is designed to efficiently quench the excited electronic and ro-vibrational states of species through collisions with the walls of the pipe before they reach the ice sample. The geometry is designed in such a way that this is realized through at least four wall collisions of the atoms before leaving the pipe. In this way, "hot" species cannot reach the ice directly. All atom fluxes are in the range between $10^{11}$ and $10^{13}$ atoms $\mathrm{cm}^{-2} \mathrm{~s}^{-1}$ and the calibration procedures are described in ref. 15.

The system is designed to investigate selected surface reactions in the multilayer regime, on an optically flat gold substrate, in pure, polar, and apolar ices, and for different atom fluxes. As described in Part I, co-deposition and sequential deposition experiments can be performed using this system under fully controlled conditions. Since ices are studied in the multilayer regime, RAIR spectra are used to test the reaction routes in situ, while quadrupole mass spectrometer (QMS) data are used as a complementary technique to constrain the RAIR results.

\subsection{FORMOLISM setup}

FORMOLISM consists of an UHV main chamber and two triply differentially pumped atom lines. The main chamber contains a silicate (or graphite) substrate that can be cooled down to 6.5 K. As for SURFRESIDE ${ }^{2}$, ices are studied in situ using a Fourier Transform Infrared (FTIR) spectrometer in RAIR mode, and a quadrupole mass spectrometer. Diversely from SURFRESIDE ${ }^{2}$ that mounts the QMS on the back-side of the rotatable gold substrate, the substrate in FORMOLISM can be linearly translated in front of the rotatable QMS. In several experiments, compact ASW is deposited at $110 \mathrm{~K}$ on the substrate prior to the deposition of any reactants to study the substrate effect on thin ices (i.e., sub-monolayer regime). The two atom sources are both microwave driven dissociation sources $(300 \mathrm{~W}$ at $2.50 \mathrm{GHz}$ ). The atom fluxes are characterized in Part I and elsewhere. ${ }^{12,24}$ FORMOLISM uses TPD and QMS data as main techniques to investigate surface reaction schemes. Due to the lower signal-to-noise ratio of the RAIR data acquired in 
the sub-monolayer regime, RAIR spectra are usually used to constrain the results obtained from the more sensitive, however, non-in situ QMS technique.

SURFRESIDE $^{2}$ and FORMOLISM are two complementary and unique systems that are combined to investigate interstellar relevant surface reaction schemes under an extensive physical and chemical range of conditions. Table 1 lists the experiments performed using the two systems to study the destruction of $\mathrm{NO}_{2}$ molecules at astronomically relevant temperatures. In the next section, we show the results of the experiments listed in Table 1. The possible destruction routes are presented in the Discussion section. The paper completes with astrophysical implications and conclusions.

\section{Results}

\section{$3.1 \quad \mathrm{NO}_{2}+\mathrm{H}$}

Fig. 1 shows the TPD curves of $\mathrm{NO}_{2}$ (mass 46, left panel), $\mathrm{H}_{2} \mathrm{O}$ (mass 18, central panel), and $\mathrm{NH}_{2} \mathrm{OH}$ (mass 33, right panel) for two different sequential deposition experiments: $2.5 \mathrm{ML}$ of $\mathrm{NO}_{2}$ (black line) and 2.5 $\mathrm{ML}$ of $\mathrm{NO}_{2}+10 \mathrm{ML}$ of $\mathrm{H}$ atoms (red line). A graphite plate held at $10 \mathrm{~K}$ is used as a substrate. To have similar background water contributions to the total water observed in both experiments (central panel), TPD experiments were started in both cases 50 minutes after the ice was deposited. Therefore, for the first experiment (2.5 $\mathrm{ML}$ of $\mathrm{NO}_{2}$ ) the ice was left at $10 \mathrm{~K}$ for 50 minutes before the TPD started, while for the second experiment (2.5 $\mathrm{ML}$ of $\mathrm{NO}_{2}+10 \mathrm{ML}$ of $\mathrm{H}$ ) the ice was exposed to $\mathrm{H}$ atoms for 50 minutes with a $\mathrm{H}$-flux of $3.3 \times 10^{12}$ atoms $\mathrm{cm}^{-1} \mathrm{~s}^{-1}$ and the TPD was started afterward.

Fig. 1 shows the destruction of $\mathrm{NO}_{2}$ upon hydrogenation of the ice, and the formation of new molecules. In particular, the $\mathrm{NO}_{2}$ desorption peak is attenuated and shifted toward higher temperatures in the hydrogenation experiment (red curve) compared to the deposition of pure $\mathrm{NO}_{2}$ (black curve), indicating that new species are formed in the ice. In our experiments, the desorption temperatures of $\mathrm{NO}_{2}, \mathrm{H}_{2} \mathrm{O}$, and $\mathrm{NH}_{2} \mathrm{OH}$ are between 110 and $140 \mathrm{~K}, 140$ and $170 \mathrm{~K}$, and 225 and $265 \mathrm{~K}$, respectively. Congiu et al. ${ }^{12}$ showed that $\mathrm{NH}_{2} \mathrm{OH}$ desorbs between 180 and $200 \mathrm{~K}$ under UHV conditions. The higher desorption temperature of $\mathrm{NH}_{2} \mathrm{OH}$ reported here indicates that either mass 33 is due to $\mathrm{NH}_{2} \mathrm{OH}$ trapped by a less volatile unidentified species formed in the ice, or mass 33 is actually caused by an unidentified species that desorb at higher temperatures than $\mathrm{NH}_{2} \mathrm{OH}$ but fractionates via a $\mathrm{NH}_{2} \mathrm{OH}$ channel in the QMS.

A comparison between infrared spectra of pure $\mathrm{NO}_{2}, \mathrm{H}_{2} \mathrm{O}$, and $\mathrm{NH}_{2} \mathrm{OH}$ deposition, and co-deposition of $\mathrm{NO}_{2}+\mathrm{H}$ in the ratio of $\sim 1: 10$ confirms the TPD results shown in Fig. 1 (see Fig. 2). In particular, spectrum (a) shows the dimerization of solid $\mathrm{NO}_{2}$, while spectrum (b) presents all the absorption peaks due to $\mathrm{H}_{2} \mathrm{O}$ and $\mathrm{NH}_{2} \mathrm{OH}$ as confirmed in spectra (c) and (d). Table 2 lists all the absorption features visible in Fig. 2. The results shown in Fig. 1 and 2 are obtained under different experimental conditions: Fig. 1 - silicon substrate and sequential deposition; Fig. 2 - gold substrate and co-deposition. The ice thickness is similar for both experiments $(\sim 3 \mathrm{ML})$, while the analysis techniques are different: TPD with QMS (Fig. 1) and in situ FT-RAIR measurements (Fig. 2). Since both experiments use a high $\mathrm{H}$-atom coverage, the final result in both experiments is the formation of saturated species, such as water and hydroxylamine. This indicates that independent of these experimental settings, the reaction $\mathrm{NO}_{2}+\mathrm{H} \rightarrow \mathrm{NO}+\mathrm{OH}$ is efficient in the solid phase.

3.1.1 $\mathrm{NO}_{2}+\mathrm{H}$ in an apolar ice. The $\mathrm{NO}_{2}+\mathrm{H}$ reaction is studied in an apolar ice by co-depositing $\mathrm{NO}_{2},{ }^{13} \mathrm{CO}$, and $\mathrm{H}$ atoms onto a gold substrate at $15 \mathrm{~K}$. The choice of an astrochemically relevant CO ice matrix allows for the study of different reactants formed through hydrogenation of the ice and, therefore, a better understanding of the full reaction scheme. Fig. 3 shows the co-deposition spectrum of ${ }^{13} \mathrm{CO}+\mathrm{H}=$ $1: 1.5$ at $13.5 \mathrm{~K}$ (a) compared to the co-deposition of $\mathrm{NO}_{2}+{ }^{13} \mathrm{CO}=$ $1: 50$ (b) and the co-deposition of $\mathrm{NO}_{2}+{ }^{13} \mathrm{CO}+\mathrm{H}=1: 50: 10$ (c), both at $15 \mathrm{~K}$. All these experiments have the same $\mathrm{H}$-atom fluence $\left(1.5 \times 10^{16}\right.$ atoms $\left.\mathrm{cm}^{-2}\right)$ as well as the same $\mathrm{NO}_{2}$ and ${ }^{13} \mathrm{CO}$ deposition rates $\left(0.05\right.$ and $\left.2.5 \mathrm{~L} \mathrm{~min}^{-1}\right)$ when deposited together. Therefore, a comparison of these spectra gives a qualitative picture of the destruction of solid $\mathrm{NO}_{2}$ and allows for the identification of new species formed through the hydrogenation of the ice. In particular, spectrum (a) confirms the formation of formaldehyde after hydrogenation of ${ }^{13} \mathrm{CO}$ ice $;{ }^{25-27}$ spectrum (b) clearly shows all the carbon monoxide isotopologues, as well as the $\mathrm{NO}_{2}$ monomer, $\mathrm{N}_{2} \mathrm{O}_{3}$ and $\mathrm{N}_{2} \mathrm{O}_{4}$. The strong $\mathrm{NO}_{2}$ feature seen in spectrum (b) at $1612 \mathrm{~cm}^{-1}$ almost disappears in spectrum (c) where new features due to ${ }^{13} \mathrm{CO}_{2}, \mathrm{HO}^{13} \mathrm{CO}, \mathrm{H}^{13} \mathrm{COOH}, \mathrm{HNO}$, and $\mathrm{NH}_{2} \mathrm{OH}$ show up. The presence of $\mathrm{HNO}$ in the ice can be explained by the nature of the co-deposition experiments, where the continuous deposition of new molecules on the cold ice surface causes some of the formed HNO to get trapped in the ice matrix, where it is not further converted into $\mathrm{NH}_{2} \mathrm{OH}$ as shown in ref. 11-13. The formation of species not previously detected during the hydrogenation of pure $\mathrm{NO}_{2}$ or pure $\mathrm{CO}$ indicates that the interaction of the two reaction pathways leads toward a higher degree of chemical complexity in the ice. The full reaction scheme leading to the formation of the aforementioned species is presented in the Discussion section, while a list of spectral features and their assignments is shown in Table 2 .

Although $\mathrm{NO}_{2}$ is mixed in a ${ }^{13} \mathrm{CO}$ matrix $\left(\mathrm{NO}_{2} \ll{ }^{13} \mathrm{CO}\right)$, the only hydrogenation products observed in spectrum (c) of Fig. 3 are due to the hydrogenation of $\mathrm{NO}_{2}$ : i.e., the hydrogenation products of solid ${ }^{13} \mathrm{CO}\left(\mathrm{H}_{2}{ }^{13} \mathrm{CO}\right.$ and $\left.{ }^{13} \mathrm{CH}_{3} \mathrm{OH}\right)$ are under the detection limit. $\mathrm{HO}^{13} \mathrm{CO},{ }^{13} \mathrm{CO}_{2}$, and $\mathrm{H}^{13} \mathrm{COOH}$ are all products of the reaction $\mathrm{OH}+{ }^{13} \mathrm{CO}$ as is discussed in Section 4 . Thus, the reaction $\mathrm{NO}_{2}+\mathrm{H}$ is more efficient than reaction ${ }^{13} \mathrm{CO}+\mathrm{H}$ for the experimental settings studied here, and proceeds most likely barrierless or with a small barrier in the solid phase.

3.1.2 H-atom flux dependence. Fig. 4 shows $\mathrm{NO}_{2}:{ }^{13} \mathrm{CO}$ hydrogenation experiments for different $\mathrm{H}$-atom fluxes: spectrum (a) is a co-deposition of $\mathrm{NO}_{2}:{ }^{13} \mathrm{CO}=1: 50$ at $15 \mathrm{~K}$ used for comparison with spectrum (b), that is the low H-atom flux co-deposition experiment $\left(\mathrm{NO}_{2}:{ }^{13} \mathrm{CO}: \mathrm{H}=1: 25: 2\right)$, and with spectrum (c), that is the high $\mathrm{H}$-atom flux co-deposition 


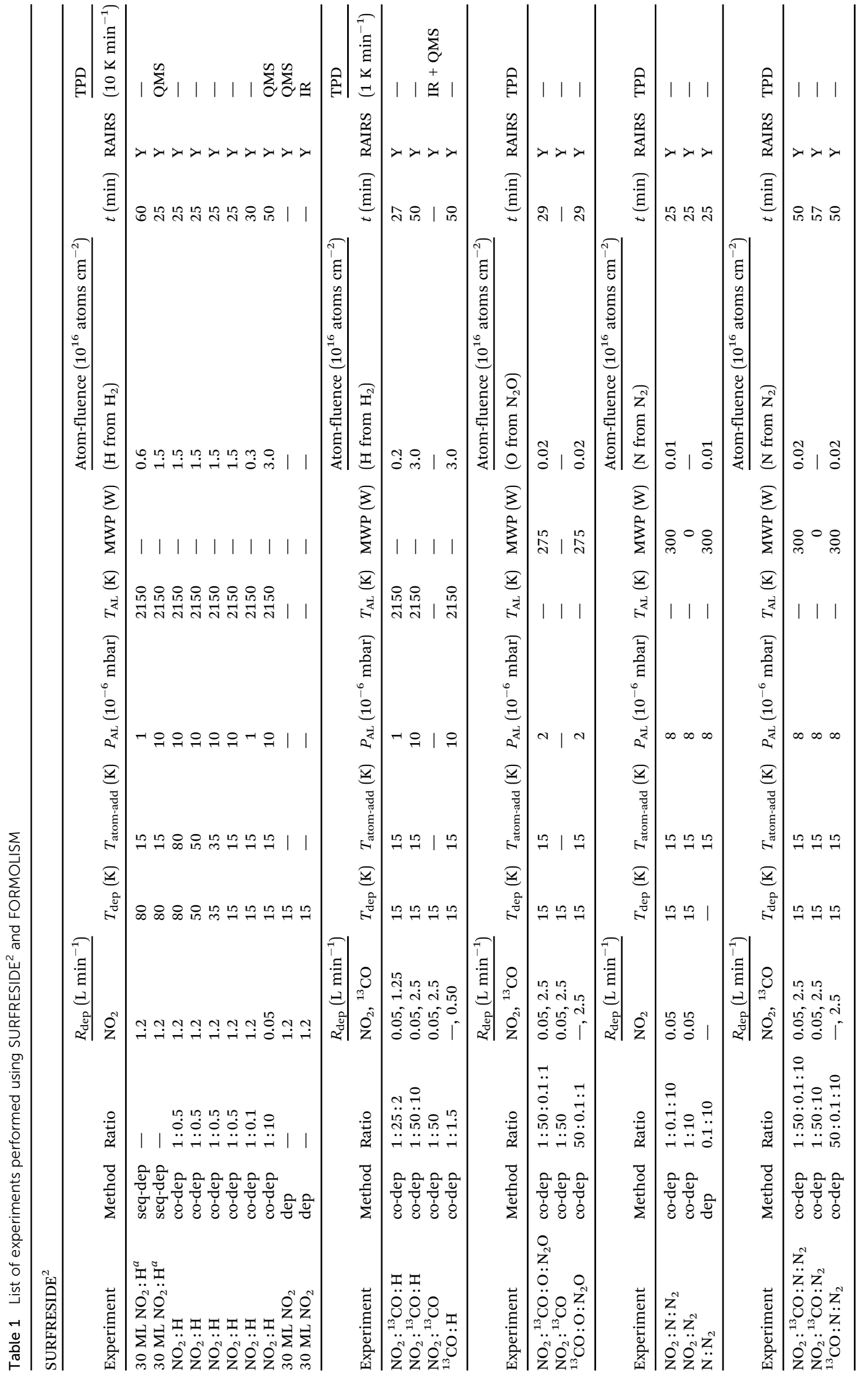




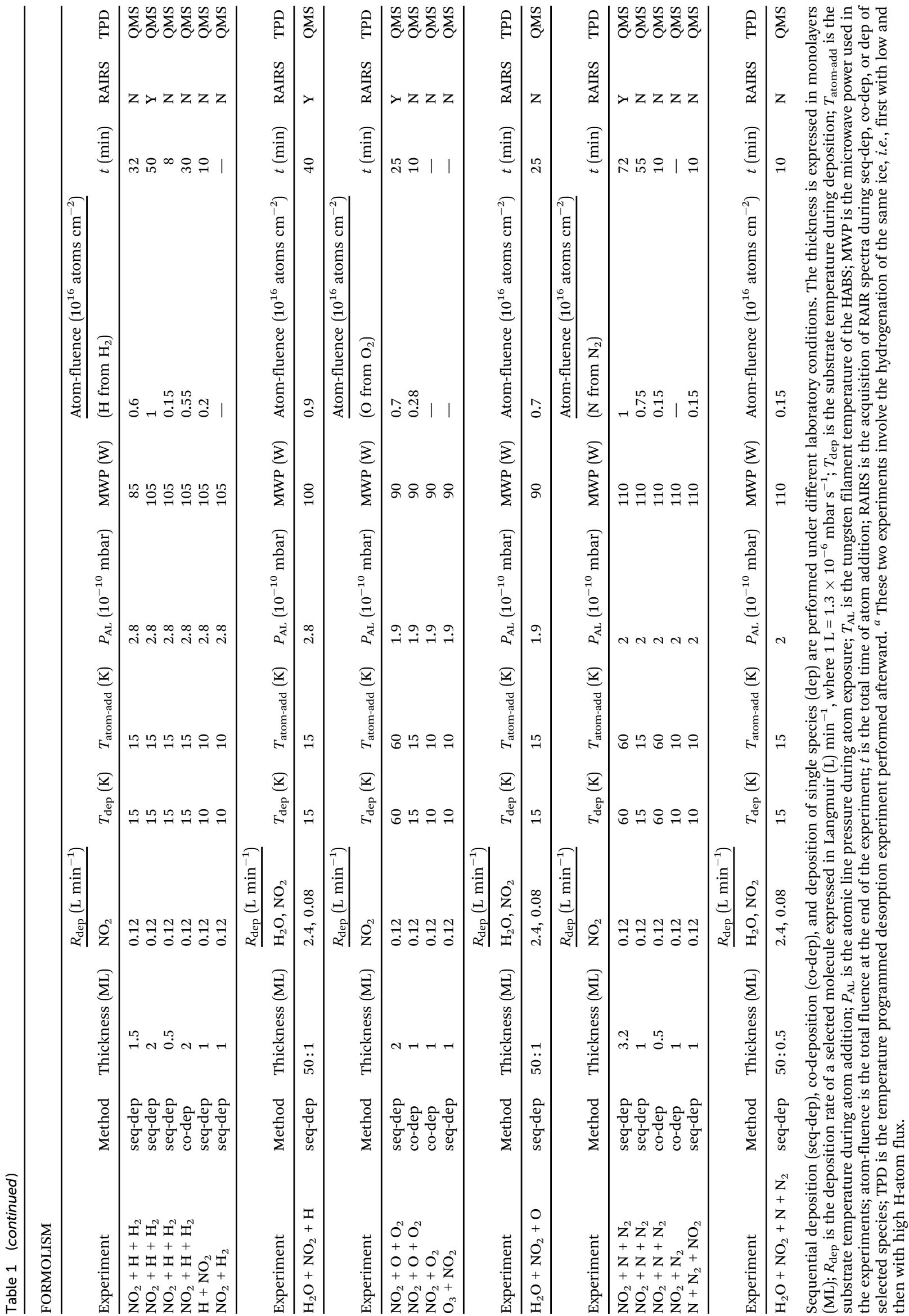




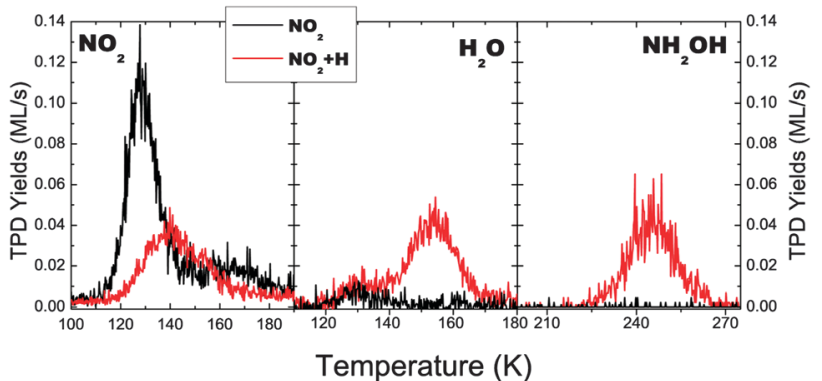

Fig. 1 TPD curves of $\mathrm{NO}_{2}\left(\mathrm{~m} / \mathrm{z}=46\right.$, left panel), $\mathrm{H}_{2} \mathrm{O}(\mathrm{m} / \mathrm{z}=18$, central panel), and $\mathrm{NH}_{2} \mathrm{OH}(\mathrm{m} / \mathrm{z}=33$, right panel) for two different co-deposition experiments at $10 \mathrm{~K}: 2.5 \mathrm{ML}$ of $\mathrm{NO}_{2}$ (black line) and $2.5 \mathrm{ML}$ of $\mathrm{NO}_{2}+10 \mathrm{ML}$ of $\mathrm{H}$ atoms (red line).

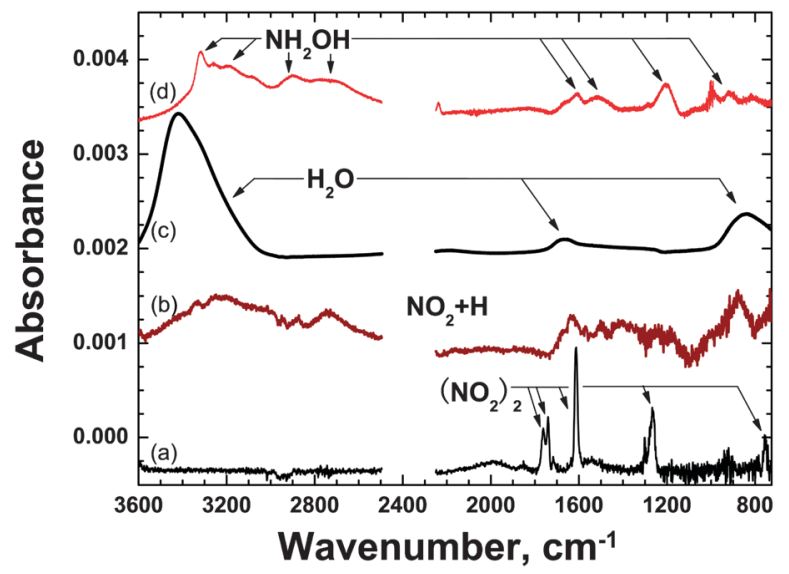

Fig. 2 Four RAIR spectra at $15 \mathrm{~K}$ of: (a) $3 \mathrm{ML}$ of $\mathrm{NO}_{2}$; (b) $\mathrm{NO}_{2} \mathrm{co}$-deposited with $\mathrm{H}$ atoms with a ratio of $\sim 1: 10$ and a $\mathrm{H}$-atom flux of $1 \times 10^{13}$ atoms $\mathrm{cm}^{-2} \mathrm{~s}^{-1}$; (c) a spectrum of pure $\mathrm{H}_{2} \mathrm{O}$ ice; and (d) pure $\mathrm{NH}_{2} \mathrm{OH}$ ice obtained by co-depositing $\mathrm{NO}$ molecules and $\mathrm{H}$ atoms with a ratio of $1: 10$ (see ref. 12 and 13).

experiment $\left(\mathrm{NO}_{2}:{ }^{13} \mathrm{CO}: \mathrm{H}=1: 50: 10\right)$. The $\mathrm{NO}_{2}$ monomer, $\mathrm{N}_{2} \mathrm{O}_{4}$, and all the isotopologues of ${ }^{13} \mathrm{CO}$ are present in spectrum (a). Spectrum (b) shows that the $\mathrm{NO}_{2}$ monomer is consumed by the low $\mathrm{H}$-atom flux to form the NO monomer, HNO, and ${ }^{13} \mathrm{CO}_{2}$. At high $\mathrm{H}$-atom fluences and for a high $\mathrm{H}$-atom flux, the $\mathrm{NO}_{2}$ concentration is further reduced, most of the formed $\mathrm{NO}$ is converted into $\mathrm{NH}_{2} \mathrm{OH}$, also the $\mathrm{HO}^{13} \mathrm{CO}$ complex is above the detection limit as well as $\mathrm{H}^{13} \mathrm{COOH}$, and the ${ }^{13} \mathrm{CO}_{2}$ signal is further increased. The use of different $\mathrm{H}$-atom fluxes in co-deposition experiments allows for the identification of the single steps of the reaction routes involved in the experiments as extensively discussed in ref. 47 , and thus helps understanding the formation pathway of second generation molecules such as $\mathrm{NH}_{2} \mathrm{OH}$.

\section{$3.2 \mathrm{NO}_{2}+\mathrm{O}$}

As for the hydrogenation of $\mathrm{NO}_{2}, \mathrm{NO}_{2}+\mathrm{O}$ is studied in an apolar astrochemically relevant $\mathrm{CO}$ ice at $15 \mathrm{~K}$. Fig. 5 shows the co-deposition spectrum of ${ }^{13} \mathrm{CO}+\mathrm{O}=50: 0.1$ with the O-atom beam arising from $\mathrm{N}_{2} \mathrm{O}$ plasma dissociation $\left(\mathrm{O}: \mathrm{N}_{2} \mathrm{O}=0.1: 1\right)$ (a), compared to the co-deposition of $\mathrm{NO}_{2}+{ }^{13} \mathrm{CO}=1: 50$ (b),
Table 2 Assigned infrared features with their corresponding references

\begin{tabular}{|c|c|c|c|}
\hline Frequency $/ \mathrm{cm}^{-1}$ & Species & Mode & Ref. \\
\hline 751 & $\mathrm{~N}_{2} \mathrm{O}_{4} / \mathrm{NO}_{2}$ & $\nu_{12} / \nu_{2}$ & 28 \\
\hline 781 & $\mathrm{~N}_{2} \mathrm{O}_{3}$ & $\nu_{4}$ & 28 \\
\hline 870 & $\mathrm{NH}_{2} \mathrm{OH}$ & $\nu_{6}$ & 29,30 \\
\hline 1041 & $\mathrm{O}_{3}$ & $\nu_{3}$ & $31-33$ \\
\hline 1117 & $\mathrm{H}^{13} \mathrm{COOH}$ & $\nu_{6}$ & 34 \\
\hline 1143 & $\mathrm{NH}_{2} \mathrm{OH}$ & $\nu_{5}$ & 29,30 \\
\hline 1167 & $\mathrm{~N}_{2} \mathrm{O}$ & $2 \nu_{2}$ & 35,36 \\
\hline 1260 & $\mathrm{~N}_{2} \mathrm{O}_{4}$ & $\nu_{11}$ & 28,37 \\
\hline 1290 & $\mathrm{~N}_{2} \mathrm{O}$ & $\nu_{1}$ & $35,36,38$ \\
\hline 1303 & $\mathrm{~N}_{2} \mathrm{O}_{3} / \mathrm{NO}_{2}$ & $\nu_{3} / \nu_{1}$ & 28,39 \\
\hline 1494 & $\mathrm{H}_{2}{ }^{13} \mathrm{CO}$ & $\nu_{3}$ & 34,40 \\
\hline 1571 & HNO & $\nu_{3}$ & 41 \\
\hline 1602 & $\mathrm{NH}_{2} \mathrm{OH}$ & $\nu_{3}$ & 29,30 \\
\hline 1615 & $\mathrm{NO}_{2} / \mathrm{N}_{2} \mathrm{O}_{3}$ & $\nu_{3} / \nu_{2}$ & $28,38 / 28,39$ \\
\hline 1693 & $\mathrm{H}_{2}{ }^{13} \mathrm{CO}$ & $\nu_{2}$ & 34,40 \\
\hline 1712 & $\mathrm{H}^{13} \mathrm{COOH}$ & $\nu_{3}$ & 34 \\
\hline 1737 & $t-(\mathrm{NO})_{2} / \mathrm{N}_{2} \mathrm{O}_{4}$ & $\nu_{1} / \nu_{9}$ & $28 / 37$ \\
\hline 1754 & $\mathrm{c}-\mathrm{HO}^{13} \mathrm{CO}$ & $\nu_{2}$ & 34 \\
\hline 1766 & $\mathrm{c}-(\mathrm{NO})_{2} / \mathrm{N}_{2} \mathrm{O}_{4}$ & $\nu_{5} / \nu_{9}$ & $28,42 / 37$ \\
\hline 1786 & $t-\mathrm{HO}^{13} \mathrm{CO}$ & $\nu_{2}$ & 34 \\
\hline $1833-1848^{a}$ & $\mathrm{~N}_{2} \mathrm{O}_{3}$ & $\nu_{1}$ & 28 \\
\hline 1850 & $\mathrm{~N}_{2} \mathrm{O}_{3}$ & $\nu_{1}$ & 28,39 \\
\hline 1875 & NO (monomer) & $\nu_{1}$ & $28,37,42$ \\
\hline 2039 & ${ }^{13} \mathrm{C}^{18} \mathrm{O}$ & $\nu_{1}$ & 43 \\
\hline 2066 & ${ }^{13} \mathrm{C}^{17} \mathrm{O}$ & $\nu_{1}$ & 43 \\
\hline 2096 & ${ }^{13} \mathrm{CO}$ & $\nu_{1}$ & 44 \\
\hline 2139 & $\mathrm{CO}$ & $\nu_{1}$ & 45 \\
\hline 2235 & $\mathrm{~N}_{2} \mathrm{O}$ & $\nu_{3}$ & $35,36,38$ \\
\hline 2280 & ${ }^{13} \mathrm{CO}_{2}$ & $\nu_{3}$ & 46 \\
\hline
\end{tabular}

${ }^{a}$ The $\mathrm{N}_{2} \mathrm{O}_{3}$ peak position shifts in different environments (see Fig. 5 and 7).

and the co-deposition of $\mathrm{NO}_{2}+{ }^{13} \mathrm{CO}+\mathrm{O}=1: 50: 0.1$ (c). All these experiments have the same O-atom fluence $(1.5 \times$ $10^{14}$ atoms $\mathrm{cm}^{-2}$ ) as well as the same $\mathrm{NO}_{2}$ and ${ }^{13} \mathrm{CO}$ deposition rates (0.05 and $2.5 \mathrm{~L} \mathrm{~min}^{-1}$, see caption Table 1$)$. Since $\mathrm{O}$ atoms are produced in a $\mathrm{N}_{2} \mathrm{O}$ plasma in the MWAS, spectrum (a) of Fig. 5 shows features due to $\mathrm{N}_{2} \mathrm{O}$, in addition to all the isotopologues of ${ }^{13} \mathrm{CO}$, and the newly formed $\mathrm{O}_{3}$ and ${ }^{13} \mathrm{CO}_{2}$. Spectrum (b) of Fig. 5 is very similar to spectrum (b) in Fig. 3 showing features of the ${ }^{13} \mathrm{CO}$ isotopologues, the $\mathrm{NO}_{2}$ monomer, $\mathrm{N}_{2} \mathrm{O}_{3}$, and $\mathrm{N}_{2} \mathrm{O}_{4}$. A comparison between spectrum (b) and (c) reveals that $\mathrm{NO}_{2}$ is destroyed during $\mathrm{O}$-atom bombardment, while the NO monomer and $\mathrm{N}_{2} \mathrm{O}_{3}$ are formed in this process (see Table 2).

A comparison between spectra (a) and (c) of Fig. 5 shows that less $\mathrm{O}_{3}$ (and ${ }^{13} \mathrm{CO}_{2}$ ) is formed when $\mathrm{NO}_{2}$ is present in the ice. Since the formation of ozone through the oxygenation of molecular oxygen is efficient, reaction $\mathrm{NO}_{2}+\mathrm{O}$ also has to be fast (barrierless or with a small barrier) in the solid phase. ${ }^{48,49}$

\section{$3.3 \mathrm{NO}_{2}+\mathrm{N}$}

Fig. 6 shows the TPD curves of $\mathrm{N}_{2} \mathrm{O}$ (mass 44, left panel), and $\mathrm{NO}_{2}$ (mass 46, right panel) for three different sequential deposition experiments: $10 \mathrm{ML}$ of $\mathrm{N}$ atoms (green line), $1 \mathrm{ML}$ of $\mathrm{NO}_{2}$ (black line), and $1 \mathrm{ML}$ of $\mathrm{NO}_{2}+10 \mathrm{ML}$ of $\mathrm{N}$ atoms (red line). A graphite surface held at $60 \mathrm{~K}$ is used as a substrate. Fig. 6 shows the destruction of $\mathrm{NO}_{2}$ and the formation of $\mathrm{N}_{2} \mathrm{O}$ upon $\mathrm{N}$-atom exposure of the ice. The $\mathrm{NO}_{2}$ desorption peak is slightly attenuated while the $\mathrm{N}_{2} \mathrm{O}$ peak shows up between 

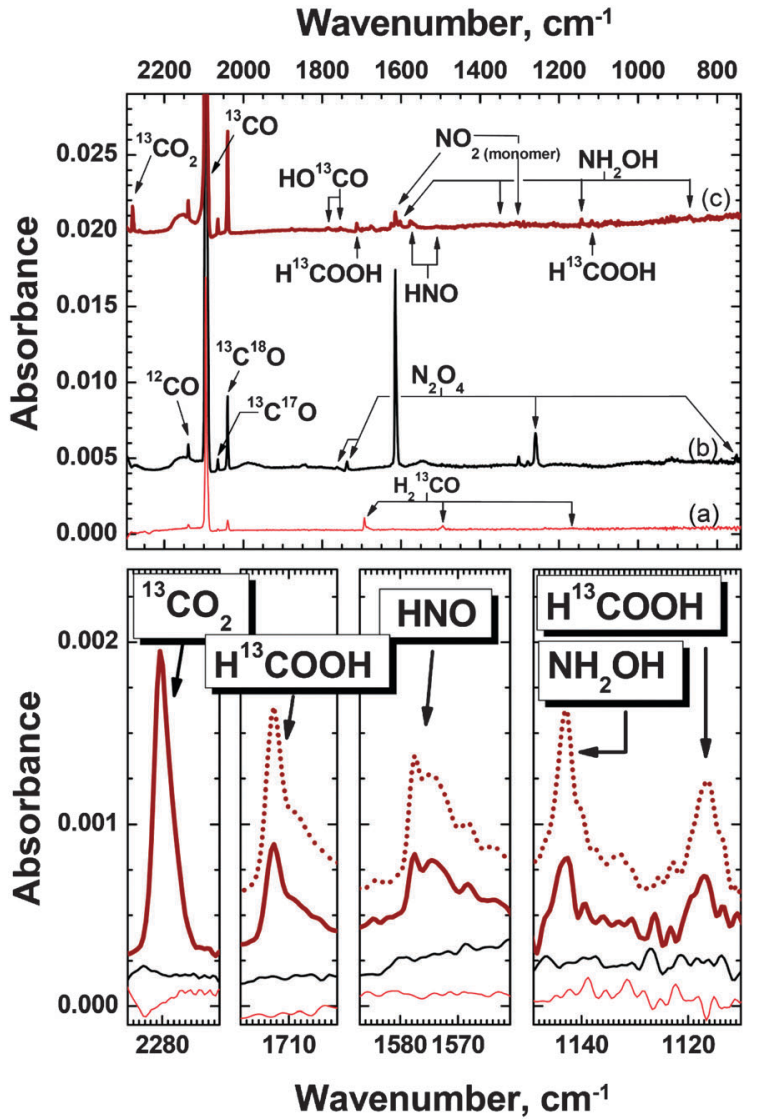

Fig. 3 Top panel: three RAIR co-deposition spectra at $15 \mathrm{~K}$ of: (a) ${ }^{13} \mathrm{CO}$ molecules and hydrogen atoms (HABS) with a ratio of $1: 1.5$ and a $\mathrm{H}$-atom fluence of $1.5 \times 10^{16}$ atoms $\mathrm{cm}^{-2}$; (b) $\mathrm{NO}_{2}$ and ${ }^{13} \mathrm{CO}$ with a ratio of 1:50; (c) $\mathrm{NO}_{2},{ }^{13} \mathrm{CO}$, and $\mathrm{H}$ atoms with a ratio of $1: 50: 10$ and the same $\mathrm{H}$-atom fluence as for spectrum (a). The insets show absorption features of solid ${ }^{13} \mathrm{CO}_{2}, \mathrm{H}^{13} \mathrm{COOH}, \mathrm{HNO}$, and $\mathrm{NH}_{2} \mathrm{OH}$. The dotted spectrum shown in the insets is from the same experiment shown in spectrum (c) at higher $\mathrm{H}$ atom fluence - i.e., twice the co-deposition time shown in spectrum (c).

70 and $80 \mathrm{~K}$ when $\mathrm{N}_{2} \mathrm{O}$ is exposed to $\mathrm{N}$ atoms, confirming that new species are formed in the ice upon $\mathrm{N}$-atom exposure.

Here, $\mathrm{NO}_{2}+\mathrm{N}$ is also studied in an apolar astrochemically relevant $\mathrm{CO}$ ice at $15 \mathrm{~K}$. Fig. 7 shows the spectrum of a ${ }^{13} \mathrm{CO}+\mathrm{N}=$ $50: 0.1$ with the $\mathrm{N}$-atom beam generated from $\mathrm{N}_{2}$ plasma dissociation $\left(\mathrm{N}: \mathrm{N}_{2}=0.1: 25\right)$ (a), compared to the co-deposition of $\mathrm{NO}_{2}+$ ${ }^{13} \mathrm{CO}+\mathrm{N}_{2}=1: 50: 10$ (b), and the co-deposition of $\mathrm{NO}_{2}+{ }^{13} \mathrm{CO}+\mathrm{N}=$ $1: 50: 0.1$ (c). All these experiments have the same $\mathrm{N}$-atom fluence $\left(1.2 \times 10^{14}\right.$ atoms $\left.\mathrm{cm}^{-2}\right)$ as well as the same $\mathrm{NO}_{2}$ and ${ }^{13} \mathrm{CO}$ deposition rates $\left(0.05\right.$ and $\left.2.5 \mathrm{~L} \mathrm{~min}^{-1}\right)$. Spectrum (b) of Fig. 7 is very similar to the spectra (b) of Fig. 3 and 5 showing features of the ${ }^{13} \mathrm{CO}$ isotopologues, the $\mathrm{NO}_{2}$ monomer, $\mathrm{N}_{2} \mathrm{O}_{3}$, and $\mathrm{N}_{2} \mathrm{O}_{4}$. A comparison between spectrum (b) and (c) reveals that $\mathrm{NO}_{2}$ is destroyed during $\mathrm{N}$-atom bombardment, while $\mathrm{N}_{2} \mathrm{O}$, the NO monomer, and $\mathrm{N}_{2} \mathrm{O}_{3}$ are formed (see Table 2).

In the next section, a comparison between the efficiency of $\mathrm{NO}_{2}+\mathrm{N}$ and $\mathrm{NO}_{2}+\mathrm{O}$ is discussed. Since the $\mathrm{H}$-atom flux is order of magnitudes higher than the $\mathrm{O}$ - and $\mathrm{N}$-atom fluxes (as in space), such a comparison cannot be easily made for the hydrogenation experiments.
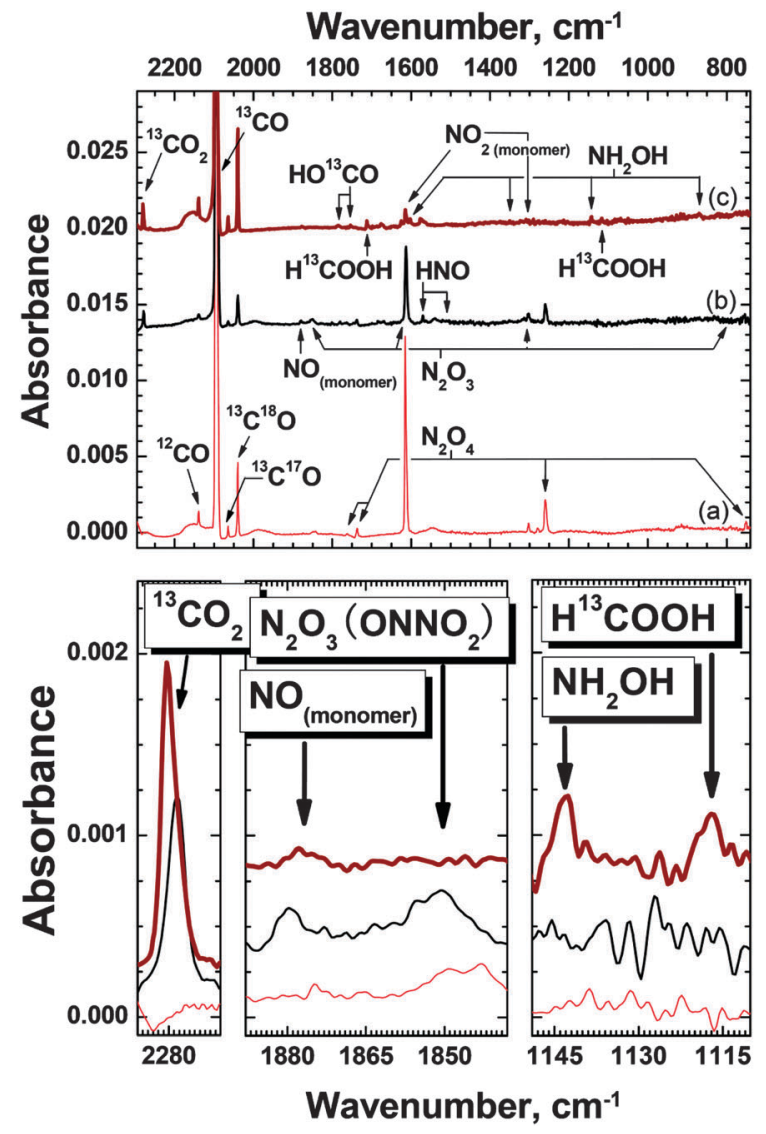

Fig. 4 Top panel: three RAIR co-deposition spectra at $15 \mathrm{~K}$ of: (a) $\mathrm{NO}_{2}$ and ${ }^{13} \mathrm{CO}$ molecules with a ratio of $1: 50$; (b) $\mathrm{NO}_{2},{ }^{13} \mathrm{CO}$, and hydrogen atoms (HABS) with a ratio of $1: 25: 2$ and an $\mathrm{H}$-atom fluence of $0.2 \times$ $10^{16}$ atoms $\mathrm{cm}^{-2}$ (low $\mathrm{H}$-atom flux); (c) $\mathrm{NO}_{2},{ }^{13} \mathrm{CO}$, and hydrogen atoms (HABS) with a ratio of $1: 50: 10$ and an $\mathrm{H}$-atom fluence of $1.5 \times$ $10^{16}$ atoms $\mathrm{cm}^{-2}$ (high $\mathrm{H}$-atom flux). The insets show absorption features of solid ${ }^{13} \mathrm{CO}_{2}, \mathrm{~N}_{2} \mathrm{O}_{3}\left(\mathrm{ONNO}_{2}\right)$, the $\mathrm{NO}$ monomer, $\mathrm{H}^{13} \mathrm{COOH}$, and $\mathrm{NH}_{2} \mathrm{OH}$.

\section{Discussion}

In Part I, we discussed the surface destruction of NO by means of surface reactions with hydrogen atoms, oxygen allotropes $\left(\mathrm{O} / \mathrm{O}_{2} / \mathrm{O}_{3}\right)$, and nitrogen atoms. The formation pathway of solid $\mathrm{NO}_{2}$ through the oxygenation of $\mathrm{NO}$ was thoroughly discussed and several reaction routes were presented (see Fig. 9 in Part I). As previously mentioned, the focus of Part II is the investigation of surface reactions involving solid $\mathrm{NO}_{2}$ at low temperatures. Here, all the experiments presented in Section 3 show the destruction of $\mathrm{NO}_{2}$ and the formation of new species such as $\mathrm{NO}, \mathrm{HNO}, \mathrm{N}_{2} \mathrm{O}, \mathrm{ONNO}_{2}, \mathrm{NH}_{2} \mathrm{OH}$, and $\mathrm{H}_{2} \mathrm{O}$. Since $\mathrm{NO}$ is also one of the reaction products, offering a renewed starting point, all the reactions discussed in Part I should also be considered in the full reaction scheme presented here.

The hydrogenation of $\mathrm{NO}_{2}$ follows:

$$
\mathrm{NO}_{2}+\mathrm{H} \rightarrow \mathrm{NO}+\mathrm{OH}
$$

Reaction (1) is found to have a small barrier in the gas phase $(<50 \mathrm{~K}) .{ }^{50}$ Our results show that reaction (1) is efficient and 


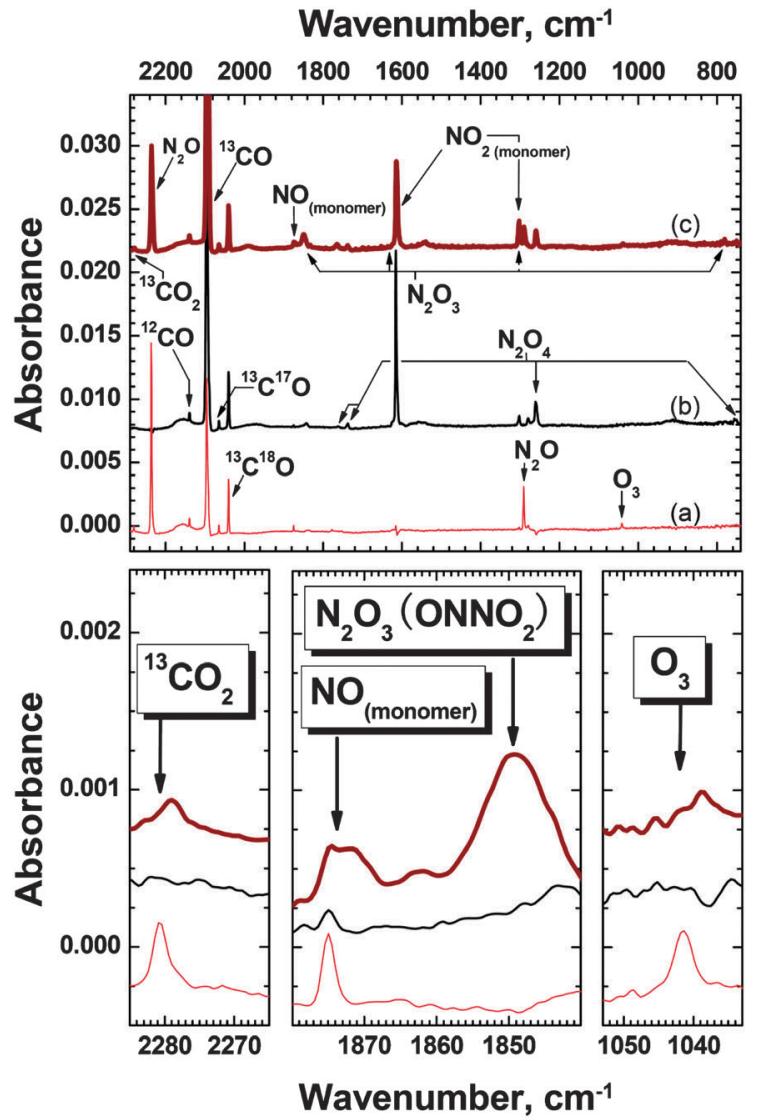

Fig. 5 Top panel: three RAIR co-deposition spectra at $15 \mathrm{~K}$ of: (a) ${ }^{13} \mathrm{CO}$ molecules and oxygen atoms (MWAS) with a ratio of 50:0.1 and an O-atom fluence of $1.5 \times 10^{14}$ atoms $\mathrm{cm}^{-2}$; (b) $\mathrm{NO}_{2}$ and ${ }^{13} \mathrm{CO}$ with a ratio of 1: 50; (c) $\mathrm{NO}_{2},{ }^{13} \mathrm{CO}$, and $\mathrm{O}$ atoms with a ratio of $1: 50: 0.1$ and the same $\mathrm{O}$-atom fluence as for spectrum (a). The insets show absorption features of solid ${ }^{13} \mathrm{CO}_{2}, \mathrm{~N}_{2} \mathrm{O}_{3}\left(\mathrm{ONNO}_{2}\right)$, the $\mathrm{NO}$ monomer, and $\mathrm{O}_{3}$.

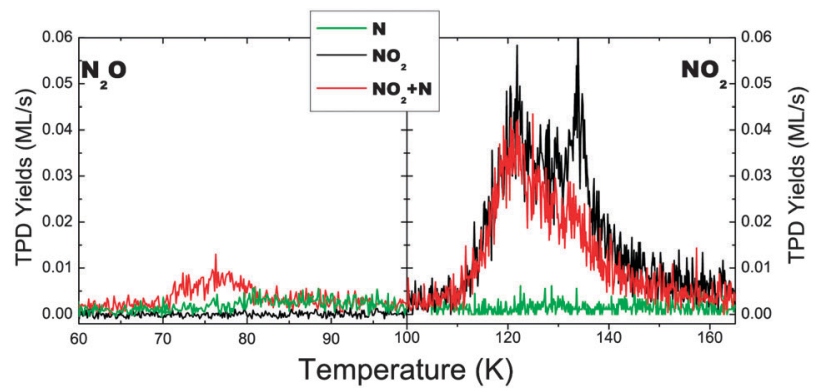

Fig. 6 TPD curves of $\mathrm{N}_{2} \mathrm{O}$ (left panel) and $\mathrm{NO}_{2}$ (right panel) for three different experiments at $60 \mathrm{~K}: 10 \mathrm{ML}$ of $\mathrm{N}$ atoms (green line), $1 \mathrm{ML}$ of $\mathrm{NO}_{2}$ (black line), and $1 \mathrm{ML}$ of $\mathrm{NO}_{2}+10 \mathrm{ML}$ of $\mathrm{N}$ atoms (red line).

leads to the formation of two reactants that act as parent species of more complex molecules observed in our experiments:

$$
\begin{gathered}
\mathrm{NO} \stackrel{\mathrm{H}}{\longrightarrow} \mathrm{HNO} \stackrel{\mathrm{H}}{\longrightarrow} \mathrm{NH}_{2} \mathrm{O} \stackrel{\mathrm{H}}{\longrightarrow} \mathrm{NH}_{2} \mathrm{OH} \\
\mathrm{OH}+\mathrm{H} \rightarrow \mathrm{H}_{2} \mathrm{O} \\
\mathrm{OH}+\mathrm{H}_{2} \rightarrow \mathrm{H}_{2} \mathrm{O}+\mathrm{H} .
\end{gathered}
$$
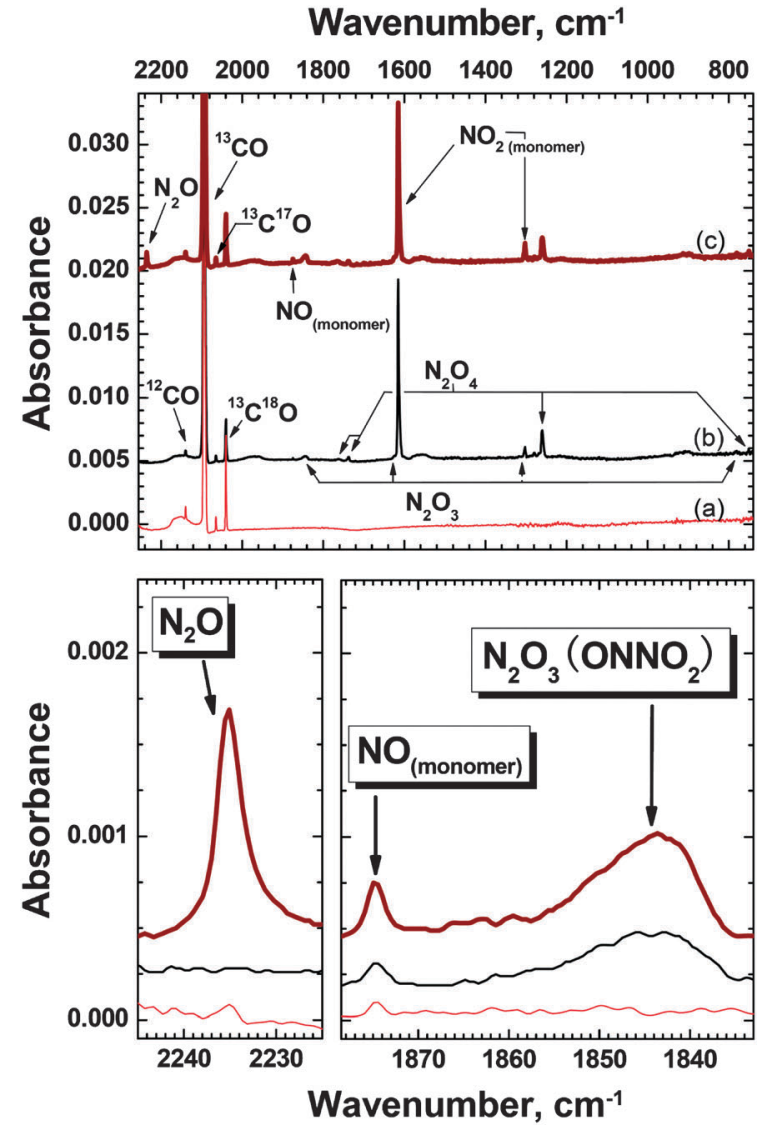

Fig. 7 Top panel: three RAIR co-deposition spectra at $15 \mathrm{~K}$ of: (a) ${ }^{13} \mathrm{CO}$ molecules and nitrogen atoms (MWAS) with a ratio of 50:0.1 and an $\mathrm{N}$-atom fluence of $1 \times 10^{14}$ atoms $\mathrm{cm}^{-2}$; (b) $\mathrm{NO}_{2}$ and ${ }^{13} \mathrm{CO}$ with a ratio of $1: 50$; (c) $\mathrm{NO}_{2},{ }^{13} \mathrm{CO}$, and $\mathrm{N}$ atoms with a ratio of $1: 50: 0.1$ and the same $\mathrm{N}$-atom fluence as for spectrum (a). The insets show absorption features of solid $\mathrm{N}_{2} \mathrm{O}, \mathrm{N}_{2} \mathrm{O}_{3}\left(\mathrm{ONNO}_{2}\right)$, and the $\mathrm{NO}$ monomer.

Congiu et al. ${ }^{11,12}$ and Fedoseev et al. ${ }^{13}$ studied reaction (2) under different laboratory conditions and found that the formation of $\mathrm{NH}_{2} \mathrm{OH}$ proceeds barrierless. Water formation has been extensively studied in the solid phase over the past decade. ${ }^{4-49,51-56}$ Fig. 1 and 2 show that $\mathrm{NH}_{2} \mathrm{OH}$ and $\mathrm{H}_{2} \mathrm{O}$ are the final products of the hydrogenation of $\mathrm{NO}_{2}$. Furthermore, if $\mathrm{NO}_{2}$ is mixed in a ${ }^{13} \mathrm{CO}$ matrix, $\mathrm{NH}_{2} \mathrm{OH}$ is still the final reaction product at high $\mathrm{H}$-atom fluences. However, the formation of water ice is in competition with other reaction routes leading to the formation of carbon dioxide and formic acid: $:^{57,58}$

$$
\begin{gathered}
\mathrm{OH}+{ }^{13} \mathrm{CO} \rightarrow \mathrm{HO}^{13} \mathrm{CO} \rightarrow{ }^{13} \mathrm{CO}_{2}+\mathrm{H} \\
\mathrm{HO}^{13} \mathrm{CO}+\mathrm{H} \rightarrow\left\{\begin{array}{l}
\mathrm{H}_{2} \mathrm{O}+{ }^{13} \mathrm{CO} \\
{ }^{13} \mathrm{CO}_{2}+\mathrm{H}_{2} \\
\mathrm{H}^{13} \mathrm{COOH},
\end{array}\right.
\end{gathered}
$$

with a purely statistical branching ratio. ${ }^{57}$ Fig. 3 shows the formation of $\mathrm{NH}_{2} \mathrm{OH}, \mathrm{HO}^{13} \mathrm{CO},{ }^{13} \mathrm{CO}_{2}$, and $\mathrm{H}^{13} \mathrm{COOH}$, while the formation of water ice is under the detection limit. 


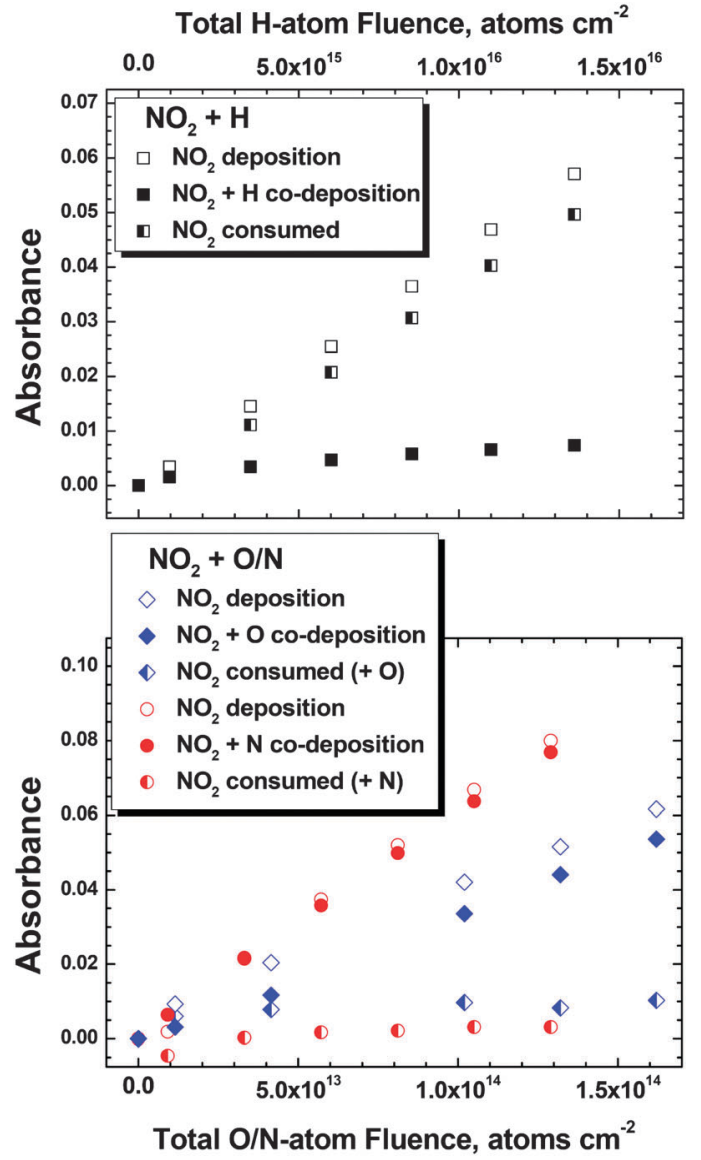

Fig. 8 Top panel: $\mathrm{NO}_{2}$ use up during co-deposition of $\mathrm{NO}_{2} \cdot{ }^{13} \mathrm{CO}: \mathrm{H}$ versus the $\mathrm{H}$-atom fluence (half-full squares). The $\mathrm{NO}_{2}$ abundance during deposition of pure $\mathrm{NO}_{2}$ (empty squares) and $\mathrm{NO}_{2}+\mathrm{H}$ (full squares) is also plotted in the same panel. Bottom panel: $\mathrm{NO}_{2}$ use up during co-deposition of $\mathrm{NO}_{2} \cdot{ }^{13} \mathrm{CO}: \mathrm{O}$ (half-full diamonds) and $\mathrm{NO}_{2} \cdot{ }^{13} \mathrm{CO}: \mathrm{N}$ (half-full circles) versus the atom fluence. As for the top panel, here the full diamonds and circles represent the $\mathrm{NO}_{2}$ abundance during $\mathrm{NO}_{2}+\mathrm{O}$ and $\mathrm{NO}_{2}+\mathrm{N}$ experiments, respectively. The empty diamonds and circles represent the $\mathrm{NO}_{2}$ abundance during deposition of pure $\mathrm{NO}_{2}$ in the $\mathrm{NO}_{2}+\mathrm{O}$ and $\mathrm{NO}_{2}+\mathrm{N}$ experiments, respectively.

$\mathrm{OH}$ radicals can also react with $\mathrm{NO}$ or $\mathrm{NO}_{2}$ to form nitrous acid or nitric acid, respectively:

$$
\begin{aligned}
& \mathrm{NO}+\mathrm{OH} \rightarrow \mathrm{HNO}_{2} \\
& \mathrm{NO}_{2}+\mathrm{OH} \rightarrow \mathrm{HNO}_{3} .
\end{aligned}
$$

Although our laboratory conditions are not suited to investigate these specific reactions ( $\mathrm{H}$ atoms $\gg \mathrm{OH}$ radicals), $\mathrm{HNO}_{2}$ and $\mathrm{HNO}_{3}$ are potentially formed in the ice. However, spectral features of $\mathrm{HNO}_{2}$ and $\mathrm{HNO}_{3}$ either overlap with the spectral bands of other molecules or are under the detection limit. Therefore, these species cannot be unambiguously identified in the ice. Joshi et $a l^{16}$ investigated in the laboratory the reaction $\mathrm{NO}+\mathrm{OH}$. In a future laboratory study we will focus on the formation of nitrogen-bearing acids in space, i.e., through the surface reactions (7) and (8).

Other reactions that lead to the formation of nitrogen oxides are:

$$
\begin{gathered}
\mathrm{NO}+\mathrm{NO} \rightarrow(\mathrm{NO})_{2} \\
\mathrm{NO}+\mathrm{NO}_{2} \rightarrow \mathrm{N}_{2} \mathrm{O}_{3} \\
\mathrm{NO}_{2}+\mathrm{NO}_{2} \rightarrow \mathrm{N}_{2} \mathrm{O}_{4} \text { or }\left(\mathrm{NO}_{2}\right)_{2} .
\end{gathered}
$$

These reactions are all discussed in Part I and are found to be barrierless in the solid phase. The choice to embed $\mathrm{NO}_{2}$ in a ${ }^{13} \mathrm{CO}$ matrix reduces the probability for reactions (9)-(11) to occur and, therefore, enables a better investigation of reactions (1)-(6) under more interstellar relevant conditions.

The hydrogenation of carbon monoxide is also visible in Fig. $3:^{25-27}$

$$
{ }^{13} \mathrm{CO} \stackrel{\mathrm{H}}{\longrightarrow} \mathrm{H}^{13} \mathrm{CO} \stackrel{\mathrm{H}}{\longrightarrow} \mathrm{H}_{2}{ }^{13} \mathrm{CO} \stackrel{\mathrm{H}}{\longrightarrow} \mathrm{H}_{3}{ }^{13} \mathrm{CO} \stackrel{\mathrm{H}}{\longrightarrow}{ }^{13} \mathrm{CH}_{3} \mathrm{OH} .
$$

Methanol is under the detection limit in all our co-deposition experiments because the used ${ }^{13} \mathrm{CO}: \mathrm{H}$ ratio leads to a low coverage of $\mathrm{H}$ atoms on the ice surface. This, combined with a low penetration depth of $\mathrm{H}$ atoms into carbon monoxide, results in an incomplete hydrogenation of ${ }^{13} \mathrm{CO}$ ice. $\mathrm{H}_{2}{ }^{13} \mathrm{CO}$ is only clearly detected when $\mathrm{NO}_{2}$ is not present in the mixture. Thus, reactions (1) and (12) are in competition when $\mathrm{NO}_{2}$ and ${ }^{13} \mathrm{CO}$ are co-deposited with $\mathrm{H}$ atoms, and reaction (1) is more efficient than reaction (12).

The oxygenation of $\mathrm{NO}_{2}$ leads to the destruction of $\mathrm{NO}_{2}$ and the formation of $\mathrm{NO}$ and $\mathrm{O}_{2}$ :

$$
\mathrm{NO}_{2}+\mathrm{O} \rightarrow \mathrm{NO}+\mathrm{O}_{2}
$$

This reaction is barrierless in the gas phase. ${ }^{59}$ Subsequently, $\mathrm{N}_{2} \mathrm{O}_{3}$ is formed through reaction (10), while NO can also react with the oxygen allotropes to form $\mathrm{NO}_{2}$, as shown in Part I:

$$
\begin{gathered}
\mathrm{NO}+\mathrm{O} \rightarrow \mathrm{NO}_{2} \\
2 \mathrm{NO}+\mathrm{O}_{2} \rightarrow 2 \mathrm{NO}_{2} \\
\mathrm{NO}+\mathrm{O}_{3} \rightarrow \mathrm{NO}_{2}+\mathrm{O}_{2} .
\end{gathered}
$$

$\mathrm{O}_{2}$ is formed in the plasma beam, through reactions (13) and (16), while $\mathrm{O}_{3}$ originates from:

$$
\mathrm{O}_{2}+\mathrm{O} \rightarrow \mathrm{O}_{3}
$$

$\mathrm{CO}_{2}$ is also formed through the reaction (see Fig. 5):

$$
{ }^{13} \mathrm{CO}+\mathrm{O} \rightarrow{ }^{13} \mathrm{CO}_{2} \text {. }
$$

Reactions (5) and (18) have been recently investigated and compared under the same laboratory conditions in ref. 15.

$\mathrm{N}_{2} \mathrm{O}$ is the final product of the nitrogenation of $\mathrm{NO}_{2}$ :

$$
\mathrm{NO}_{2}+\mathrm{N} \rightarrow \mathrm{N}_{2} \mathrm{O}+\mathrm{O} \text {. }
$$

Reactions $\mathrm{N}_{2} \mathrm{O}+\mathrm{H} / \mathrm{O} / \mathrm{N}$ have barriers and do not lead to the formation of other detectable species. ${ }^{15}$ Oxygen atoms can react with $\mathrm{NO}_{2}$ to form $\mathrm{NO}$ and $\mathrm{O}_{2}$ according to reaction (13). $\mathrm{O}$ atoms can also react with $\mathrm{NO}$ to form $\mathrm{NO}_{2}$ through reaction (14) or with an $\mathrm{N}$ atom to form $\mathrm{NO}$, although the latter reaction has not been unambiguously tested in the laboratory yet. $\mathrm{N}_{2} \mathrm{O}_{3}$ is formed through reaction (10). As discussed in Part I, the nitrogenation of NO leads to the formation of:

$$
\mathrm{NO}+\mathrm{N} \rightarrow \mathrm{N}_{2}+\mathrm{O}
$$

Reactions (19) and (20) are found to be both barrierless in the gas-phase. ${ }^{60}$ However, Fig. 6 shows that the nitrogenation 


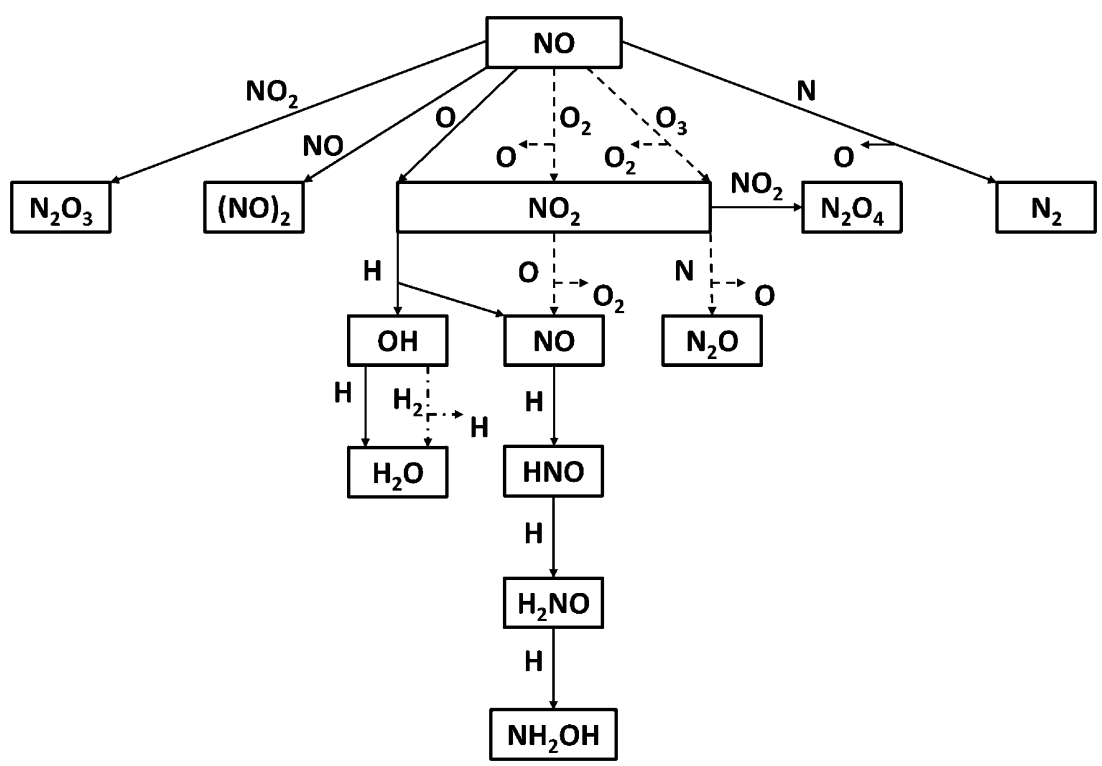

Fig. 9 Reaction scheme leading to the formation of nitrogen oxides as investigated in Parts I and II of this work. Solid lines are the reactions with no barrier; dashed lines are the reactions with a small barrier; and dashed-dotted lines are the reactions with a noticeable barrier (see also Table 3).

of $\mathrm{NO}_{2}$ is not an efficient process. This discrepancy can be explained by the dimerization of $\mathrm{NO}_{2}$ that occurs when pure $\mathrm{NO}_{2}$ is deposited in the solid phase. The dimerization process is barrierless, thus Fig. 6 only shows that reaction $\left(\mathrm{NO}_{2}\right)_{2}+\mathrm{N}$ is not efficient in the solid phase. Fig. 8 shows the $\mathrm{NO}_{2}$ use-up during co-deposition of $\mathrm{NO}_{2}:{ }^{13} \mathrm{CO}: \mathrm{H}$ (top panel), $\mathrm{NO}_{2}:{ }^{13} \mathrm{CO}: \mathrm{O}$ (bottom panel), and $\mathrm{NO}_{2}:{ }^{13} \mathrm{CO}: \mathrm{N}$ (bottom panel) versus the atom fluence. The $\mathrm{NO}_{2}$ use-up is calculated by subtracting the $\mathrm{NO}_{2}$ abundance of the $\mathrm{NO}_{2}:{ }^{13} \mathrm{CO}$ experiments from the $\mathrm{NO}_{2}$ abundance of the $\mathrm{NO}_{2}:{ }^{13} \mathrm{CO}: \mathrm{H} / \mathrm{O} / \mathrm{N}$ experiments, respectively (see Fig. 3, 5 and 7). Although as already mentioned, the efficiency of the hydrogenation reactions cannot be compared directly to that of the oxygenation and nitrogenation reactions because the $\mathrm{H}$-atom flux is orders of magnitude higher than the other atom fluxes, we can still draw conclusions on the (relative) efficiency of each surface reaction. In the Results section we showed that reaction (1) is efficient and most likely barrierless. The linear trend of the $\mathrm{NO}_{2}$ use up in the hydrogenation experiments is consistent with reaction (1) to be barrierless (top panel in Fig. 8). Moreover, since the O- and $\mathrm{N}$-atom fluxes are similar $\left(1 \times 10^{11}\right.$ atoms $\mathrm{cm}^{-2} \mathrm{~s}^{-1}$ and $8 \times$ $10^{10}$ atoms cm $\mathrm{cm}^{-2} \mathrm{~s}^{-1}$, respectively) and the $\mathrm{NO}_{2}$ deposition rates are reproducible within $\sim 20 \%$, a comparison between the $\mathrm{NO}_{2}$ use up in the oxygenation and nitrogenation experiments can be made and indicates that reaction (13) is slightly faster and, therefore, more efficient than reaction (19) (bottom panel in Fig. 8).

In our experiments, $\mathrm{O}$ atoms come from the dissociation of $\mathrm{N}_{2} \mathrm{O}$, while $\mathrm{N}$ atoms are obtained by dissociating $\mathrm{N}_{2} \cdot \mathrm{N}_{2} \mathrm{O}$ and $\mathrm{N}_{2}$ stick to the cold surface at $15 \mathrm{~K}$ during co-deposition and, therefore, become part of the ice mixture. Moreover, the dissociation rate for the two atom beams is different $\left(\mathrm{O}: \mathrm{N}_{2} \mathrm{O}=\right.$ $0.1: 1$ and $\left.\mathrm{N}: \mathrm{N}_{2}=0.1: 25\right)$. This means that, even though $\mathrm{N}_{2} \mathrm{O}$ and $\mathrm{N}_{2}$ are not participating in the surface reactions, their presence in different amounts can affect the surface coverage
Table 3 Efficiency of the main surface reactions discussed in Parts I and II

\begin{tabular}{llll}
\hline No barrier & Small barrier & Barrier & No reaction \\
\hline $\mathrm{NO}+\mathrm{H}$ & $\mathrm{NO}+\mathrm{O}_{2}$ & $\mathrm{CO}+\mathrm{H}$ & $\mathrm{NO}+\mathrm{H}_{2}$ \\
$\mathrm{NO}+\mathrm{O}$ & $\mathrm{NO}+\mathrm{O}_{3}$ & $\mathrm{H}+\mathrm{CO}+\mathrm{H}$ & $\mathrm{NO}+\mathrm{N}_{2}$ \\
$\mathrm{NO}+\mathrm{N}$ & & $\mathrm{OH}+\mathrm{H}_{2}$ & $\mathrm{NO}_{2}+\mathrm{H}_{2}$ \\
$\mathrm{NO}+\mathrm{NO}$ & & $(\mathrm{NO})_{2}+\mathrm{O}_{2}$ & $\mathrm{NO}_{2}+\mathrm{O}_{2}$ \\
$\mathrm{NO}+\mathrm{NO}_{2}$ & & $\left(\mathrm{NO}_{2}\right)_{2}+\mathrm{N}$ & $\mathrm{NO}_{2}+\mathrm{N}_{2}$ \\
$\mathrm{NO}$ & $+\mathrm{H}$ & & $\mathrm{N}_{2} \mathrm{O}+\mathrm{H}$ \\
$\mathrm{NO}_{2}+\mathrm{O}$ & & $\mathrm{N}_{2} \mathrm{O}+\mathrm{O}$ \\
$\mathrm{NO}_{2}+\mathrm{N}^{a}$ & & $\mathrm{~N}_{2} \mathrm{O}+\mathrm{N}$ \\
$\mathrm{NO}_{2}+\mathrm{NO}_{2}$ & & \\
$\mathrm{OH}+\mathrm{H}$ & & \\
${ }^{a}$ This reaction may have a small barrier. &
\end{tabular}

of $\mathrm{NO}_{2}$ and the penetration depth of $\mathrm{O}$ and $\mathrm{N}$ atoms in the ice. Thus, although our results clearly indicate that the surface reaction efficiency follows the trend $\mathrm{NO}_{2}+\mathrm{H}>\mathrm{NO}_{2}+\mathrm{O} \geq$ $\mathrm{NO}_{2}+\mathrm{N}$, the presence of $\mathrm{N}_{2} \mathrm{O}$ and $\mathrm{N}_{2}$ in the ice can partially influence the comparison of the $\mathrm{NO}_{2}$ use up shown in Fig. 8.

A schematic cartoon of all the investigated reaction routes is shown in Fig. 9. Table 3 lists the main surface reactions discussed in Parts I and II and divides them into different groups: from barrierless reactions to reactions with a high barrier that do not allow for the reaction to proceed in the solid phase at low temperatures. Given the overall complexity of the full reaction scheme, additional reaction products are expected to form as well, but for the experimental settings studied here, these clearly must be of less importance, as no clear spectroscopic or mass spectrometric data are found.

\section{Astrophysical implications}

Sub-millimeter and millimeter wavelength observations of "hot cores" - i.e., compact (few tens of AUs) regions of dense and 
warm gas where the chemistry is dominated by the evaporation of grain mantles - reveal a range of interstellar complex organic molecules, such as $\mathrm{CH}_{3} \mathrm{OH}, \mathrm{HCOOH}, \mathrm{HCOOCH}_{3}$, and $\mathrm{NH}_{2} \mathrm{CH}_{2} \mathrm{CN}^{1,61}$ The exact origin of these species is still unclear, but recent models indicate that surface reaction mechanisms are most likely the main formation channel. ${ }^{2}$ Garrod $^{2}$ showed that the gas-phase formation of glycine $\left(\mathrm{NH}_{2} \mathrm{CH}_{2} \mathrm{COOH}\right)$ in hot cores depends on the timescale of the hot-core evolution and the availability of precursor species in the gas phase. Therefore, glycine is found to form in his model almost exclusively on grain ice mantles.

A potential precursor of amino acids is hydroxylamine $\left(\mathrm{NH}_{2} \mathrm{OH}\right)$. Congiu et al. ${ }^{11,12}$ and Fedoseev et al. ${ }^{13}$ showed that hydroxylamine is efficiently formed in the solid phase under dense core conditions through reaction (2). Pulliam et al., ${ }^{62}$ using the NRAO $12 \mathrm{~m}$ telescope, could not detect $\mathrm{NH}_{2} \mathrm{OH}$ in a range of interstellar sources and found an upper limit of $8 \times$ $10^{-12}$ wrt $\mathrm{H}_{2}$ toward SgrB2(N). Due to their high desorption temperatures, rotational emission from molecules like hydroxylamine and glycine (still not unambiguously detected in the ISM) is expected for compact regions only. However, emissions from regions smaller than $\sim 5^{\prime \prime}$ are not detectable using singledish telescopes. This may explain the non-detection of these species and indicates that molecules like hydroxylamine can be potentially detected by ALMA at sub-arcsecond resolution toward bright, nearby sources with relatively narrow emission lines.

Understanding the origin of COMs is pivotal to link the formation of simple species in space to life on Earth. In Parts I and II of this work, we focus on the laboratory investigation of the surface formation of nitrogen oxides and a more complex species like hydroxylamine. In the Discussion section, we showed many reaction routes that proceed under cold cloud conditions and start from $\mathrm{NO}+\mathrm{H} / \mathrm{O} / \mathrm{O}_{2} / \mathrm{O}_{3} / \mathrm{N}$ and $\mathrm{NO}_{2}+\mathrm{H} / \mathrm{O} / \mathrm{N}$.

In this scenario, $\mathrm{NO}$ can freeze-out onto the icy grains during the dense cloud phase. ${ }^{63,64}$ NO ice can be hydrogenated in a barrierless way to form solid hydroxylamine. ${ }^{11-13}$ The NO that reacts with the oxygen allotropes in the solid phase will form efficiently $\mathrm{NO}_{2}$. The nitrogenation of $\mathrm{NO}$ will lead to the destruction of $\mathrm{NO}$ and the formation of $\mathrm{N}_{2}$. A feasible reason for the non-detection of $\mathrm{NO}_{2}$ in the ISM is a very efficient solidphase destruction pathway (i.e., photodissociation and/or nonenergetic surface reactions). We showed that $\mathrm{NO}_{2}$ can be hydrogenated in a barrierless way to form NO and $\mathrm{OH}$. These two reactants contribute to a more realistic interstellar ice to form species like $\mathrm{NH}_{2} \mathrm{OH}, \mathrm{H}_{2} \mathrm{O}, \mathrm{CO}_{2}$, and $\mathrm{HCOOH}$, as shown in this work. The oxygenation of $\mathrm{NO}_{2}$ forms again $\mathrm{NO}$ and $\mathrm{O}$ atoms, while the nitrogenation of $\mathrm{NO}_{2}$ forms also $\mathrm{N}_{2} \mathrm{O}$, another interstellar relevant species detected in the ISM. ${ }^{65}$ Thus, many of the investigated surface reaction routes lead to the formation of NO molecules and therefore $\mathrm{NH}_{2} \mathrm{OH}$. This result is in support of the formation of complex species in the solid phase and is in agreement with the most recent astrochemical models. ${ }^{2}$ Other nitrogen oxides, like $\mathrm{N}_{2} \mathrm{O}_{3}$ and $\mathrm{N}_{2} \mathrm{O}_{4}$, can be formed through the reaction of $\mathrm{NO}$ and $\mathrm{NO}_{2}$, and the reaction of two $\mathrm{NO}_{2}$ molecules, respectively. However, reactions (10) and (11) are potentially still limited by the interstellar low abundance of the parent species. Finally, nitrogen-bearing acids, like nitrous acid and nitric acid, can be formed through surface reactions (7) and (8). Although the formation of these acids was not verified here, their interstellar relevance should not be excluded.

We expect that future astrochemical models will benefit from the implementation of the efficiency of the single surface reactions investigated here and shown in Table 3. Moreover, the results found here indicate that it is worth keep searching for $\mathrm{NH}_{2} \mathrm{OH}$ in the ISM, whereas $\mathrm{NO}_{2}$ detection is not expected at this stage.

\section{Conclusions (Parts I and II)}

The surface formation and destruction of nitrogen oxides are tested under ultra high vacuum conditions, at low temperatures, and by means of RAIR spectroscopy, mass spectrometry, and TPD techniques. From this study we draw the following conclusions:

(1) $\mathrm{NO}_{2}$ is efficiently formed in the solid state via $\mathrm{NO}+\mathrm{O} / \mathrm{O}_{2} / \mathrm{O}_{3}$ reactions (Part I).

(2) The non-detection of (gaseous) $\mathrm{NO}_{2}$ in space can be related to efficient destruction mechanisms, such as surface $\mathrm{NO}_{2}+\mathrm{H} / \mathrm{O} / \mathrm{N}$ reactions (Part II).

(3) The final products of $\mathrm{NO}_{2}$ hydrogenation are $\mathrm{NH}_{2} \mathrm{OH}$ and $\mathrm{H}_{2} \mathrm{O}$. Hydroxylamine is found to be formed through a series of barrierless surface reactions as previously shown by Congiu et $a .^{11,12}$ and Fedoseev et al. ${ }^{13}$ Both water and hydroxylamine are important molecules for the formation of COMs in space (Part II).

(4) $\mathrm{N}_{2} \mathrm{O}$ is formed through the nitrogenation of $\mathrm{NO}_{2}$ and is not destroyed in reactions with $\mathrm{H}-$, O-, and $\mathrm{N}$-atoms (Part II).

(5) Several nitrogen oxides, such as $(\mathrm{NO})_{2}, \mathrm{~N}_{2} \mathrm{O}_{3}$, and $\mathrm{N}_{2} \mathrm{O}_{4}$, are formed through surface $\mathrm{NO}+\mathrm{H} / \mathrm{O} / \mathrm{O}_{2} / \mathrm{O}_{3} / \mathrm{N}$ and $\mathrm{NO}_{2}+$ $\mathrm{H} / \mathrm{O} / \mathrm{N}$ reactions due to a high concentration of parent species (Parts I and II).

(6) Surface coverage (submonolayer and multilayer regimes) has a small but noticeable impact on the final products. For instance, dimerization reactions are most likely to occur in a multilayer regime rather than in submonolayer thick ices (Parts I and II).

(7) Different substrates (silicate, graphite, compact ASW ice, and gold) and ice composition (pure ices, polar and apolar mixtures) do not affect the results in a detectable way (Parts I and II).

(8) Table 3 lists the efficiency of all the investigated reaction routes (see Fig. 9) and therefore can be used as an input in astrochemical models to better understand the formation and evolution of nitrogen oxides in space (Parts I and II).

(9) We expect ALMA to be ideally suited to detect species like hydroxylamine at sub-arcsecond resolution toward bright, nearby sources with relative narrow emission lines.

\section{Acknowledgements}

The SLA group has received funding from the European Community's Seventh Framework Programme (FP7/2007-2013) 
under grant agreement no. 238258, the Netherlands Research School for Astronomy (NOVA), the Netherlands Organization for Scientific Research (NWO) through a VICI grant, and within the Dutch Astrochemistry Network. The LERMA-LAMAp team acknowledges support from the European Community's Seventh Framework Programme (FP7/2007-2013) under grant agreement no. 238258, the national PCMI programme founded by CNRS. Support for S.I. from the Niels Stensen Fellowship and the Marie Curie Fellowship (FP7-PEOPLE-2011-IOF-300957) is gratefully acknowledged.

\section{References}

1 E. Herbst and E. F. van Dishoeck, Annu. Rev. Astron. Astrophys., 2009, 47, 427.

2 R. T. Garrod, Astrophys. J., 2013, 765, 60.

3 E. F. van Dishoeck and G. A. Blake, Annu. Rev. Astron. Astrophys., 1998, 36, 317.

4 P. Theulé, F. Duvernay, G. Danger, F. Borget, J. B. Bossa, V. Vinogradoff, F. Mispelaer and T. Chiavassa, Adv. Space Res., 2013, 52, 1567.

5 S. B. Charnley, A. G. G. M. Tielens and T. J. Millar, Astrophys. J., Lett., 1992, 399, L71.

6 C. Qi, K. I. Öberg, D. J. Wilner, P. D’Alessio, E. Bergin, S. M. Andrews, G. A. Blake, M. R. Hogerheijde and E. F. van Dishoeck, Science, 2013, 341, 630.

7 P. Boduch, A. Domaracka, D. Fulvio, T. Langlinay, X. Y. Lv, M. E. Palumbo, H. Rothard and G. Strazzulla, Astron. Astrophys., 2012, 544, A30.

8 D. Sicilia, S. Ioppolo, T. Vindigni, G. A. Baratta and M. E. Palumbo, Astron. Astrophys., 2012, 543, A155.

9 K. Hiraoka, A. Yamashita, Y. Yachi, K. Aruga, T. Sato and H. Muto, Astrophys. J., 1995, 443, 363.

10 H. Hidaka, M. Watanabe, A. Kouchi and N. Watanabe, Phys. Chem. Chem. Phys., 2011, 13, 15798.

11 E. Congiu, G. Fedoseev, S. Ioppolo, F. Dulieu, H. Chaabouni, S. Baouche, J. L. Lemaire, C. Laffon, P. Parent and T. Lamberts, et al., Astrophys. J., Lett., 2012, 750, L12.

12 E. Congiu, H. Chaabouni, C. Laffon, P. Parent, S. Baouche and F. Dulieu, J. Chem. Phys., 2012, 137, 054713.

13 G. Fedoseev, S. Ioppolo, T. Lamberts, J. F. Zhen, H. M. Cuppen and H. Linnartz, J. Chem. Phys., 2012, 137, 054714.

14 M. Minissale, E. Congiu, S. Baouche, H. Chaabouni, A. Moudens, F. Dulieu, G. Manicó and V. Pirronello, Chem. Phys. Lett., 2013, 565, 52.

15 S. Ioppolo, G. Fedoseev, T. Lamberts, C. Romanzin and H. Linnartz, Rev. Sci. Instrum., 2013, 84, 073112.

16 P. R. Joshi, E.-L. Zins and L. Krim, Mon. Not. R. Astron. Soc., 2012, 419, 1713.

17 M. Minissale, G. Fedoseev, E. Congiu, S. Ioppolo, F. Dulieu and H. Linnartz, Phys. Chem. Chem. Phys., 2014, DOI: 10.1039/c3cp54917h.

18 D. McElroy, C. Walsh, A. J. Markwick, M. A. Cordiner, K. Smith and T. J. Millar, Astron. Astrophys., 2013, 550, A36.

19 K. G. Tschersich and V. von Bonin, J. Appl. Phys., 1998, 84, 4065 .
20 K. G. Tschersich, J. Appl. Phys., 2000, 87, 2565.

21 K. G. Tschersich, J. P. Fleischhauer and H. Schuler, J. Appl. Phys., 2008, 104, 034908.

22 A. Schmidt, J. Offermann and R. Anton, Thin Solid Films, 1996, 281, 105.

23 R. Anton, T. Wiegner, W. Naumann, M. Liebmann, C. Klein and C. Bradley, Rev. Sci. Instrum., 2000, 71, 1177.

24 L. Amiaud, J. H. Fillion, S. Baouche, F. Dulieu, A. Momeni and J. L. Lemaire, J. Chem. Phys., 2006, 124, 094702.

25 K. Hiraoka, N. Ohashi, Y. Kihara, K. Yamamoto, T. Sato and A. Yamashita, Chem. Phys. Lett., 1994, 229, 408.

26 N. Watanabe and A. Kouchi, Astrophys. J., Lett., 2002, 571, L173.

27 G. W. Fuchs, H. M. Cuppen, S. Ioppolo, S. E. Bisschop, S. Andersson, E. F. van Dishoeck and H. Linnartz, Astron. Astrophys., 2009, 505, 629.

28 W. G. Fateley, H. A. Bent and B. Crawford, Jr., J. Chem. Phys., 1959, 31, 204.

29 R. Withnall and L. Andrews, J. Phys. Chem., 1988, 92, 2155. 30 G. A. Yeo and T. A. Ford, J. Mol. Struct., 1990, 217, 307.

31 P. Brosset, R. Dahoo, B. Gauthierroy, L. Abouafmarguin and A. Lakhlifi, Chem. Phys., 1993, 172, 315.

32 H. Chaabouni, L. Schriver-Mazzuoli and A. Schriver, Low Temp. Phys., 2000, 26, 712.

33 C. J. Bennett and R. I. Kaiser, Astrophys. J., 2005, 635, 1362. 34 D. E. Milligan and M. E. Jacox, J. Chem. Phys., 1971, 54, 927. 35 D. A. Dows, J. Chem. Phys., 1957, 26, 745.

36 A. Łpiński, J. Spanget-Larsen, J. Waluk and J. G. Radziszewski, J. Chem. Phys., 2001, 115, 1757.

37 R. F. Holland and W. B. Maier II, J. Chem. Phys., 1983, 78, 2928.

38 C. S. Jamieson, C. J. Bennett, A. M. Mebel and R. I. Kaiser, Astrophys. J., 2005, 624, 436.

39 E. M. Nour, L. H. Chen and J. Laane, J. Phys. Chem., 1983, 87, 1113.

40 M. M. Wohar and P. W. Jagodzinski, J. Mol. Spectrosc., 1991, 148, 13.

41 M. E. Jacox and D. E. Milligan, J. Mol. Spectrosc., 1973, 48, 536 .

42 E. M. Nour, L. H. Chen, M. M. Strube and J. Laane, J. Phys. Chem., 1984, 88, 756.

43 M. J. Loeffler, G. A. Baratta, M. E. Palumbo, G. Strazzulla and R. A. Baragiola, Astron. Astrophys., 2005, 435, 587.

44 G. E. Ewing and G. C. Pimentel, J. Chem. Phys., 1961, 35, 925. 45 S. A. Sandford, L. J. Allamandola, A. G. G. M. Tielens and G. J. Valero, Astrophys. J., 1988, 329, 498.

46 C. V. Berney and D. F. Eggers, Jr., J. Chem. Phys., 1964, 40, 990. 47 H. M. Cuppen, S. Ioppolo, C. Romanzin and H. Linnartz, Phys. Chem. Chem. Phys., 2010, 12, 12077.

48 H. Mokrane, H. Chaabouni, M. Accolla, E. Congiu, F. Dulieu, M. Chehrouri and J. L. Lemaire, Astrophys. J., Lett., 2009, 705, L195.

49 C. Romanzin, S. Ioppolo, H. M. Cuppen, E. F. van Dishoeck and H. Linnartz, J. Chem. Phys., 2011, 134, 084504.

50 M.-C. Su, S. S. Kumaran, K. P. Lim, J. V. Michael, A. F. Wagner, L. B. Harding and D.-C. Fang, J. Phys. Chem. A, 2002, 106, 8261. 
51 N. Miyauchi, H. Hidaka, T. Chigai, A. Nagaoka, N. Watanabe and A. Kouchi, Chem. Phys. Lett., 2008, 456, 27.

52 S. Ioppolo, H. M. Cuppen, C. Romanzin, E. F. van Dishoeck and H. Linnartz, Astrophys. J., 2008, 686, 1474.

53 E. Matar, E. Congiu, F. Dulieu, A. Momeni and J. L. Lemaire, Astron. Astrophys., 2008, 492, L17.

54 S. Ioppolo, H. M. Cuppen, C. Romanzin, E. F. van Dishoeck and H. Linnartz, Phys. Chem. Chem. Phys., 2010, 12, 12065.

55 F. Dulieu, L. Amiaud, E. Congiu, J. Fillion, E. Matar, A. Momeni, V. Pirronello and J. L. Lemaire, Astron. Astrophys., 2010, 512, A30.

56 Y. Oba, N. Watanabe, T. Hama, K. Kuwahata, H. Hidaka and A. Kouchi, Astrophys. J., 2012, 749, 67.

57 S. Ioppolo, H. M. Cuppen, E. F. van Dishoeck and H. Linnartz, Mon. Not. R. Astron. Soc., 2011, 410, 1089.

58 S. Ioppolo, Y. van Boheemen, H. M. Cuppen, E. F. van Dishoeck and H. Linnartz, Mon. Not. R. Astron. Soc., 2011, 413, 2281.
59 R. Atkinson, D. L. Baulch, R. A. Cox, J. N. Crowley, R. F. Hampson, R. G. Hynes, M. E. Jenkin, M. J. Rossi and J. Troe, Atmos. Chem. Phys., 2004, 4, 1461.

60 P. O. Wennberg, J. G. Anderson and D. K. Weisenstein, J. Geophys. Res., 1994, 99, 18839.

61 A. Belloche, K. M. Menten, C. Comito, H. S. P. Müller, P. Schilke, J. Ott, S. Thorwirth and C. Hieret, Astron. Astrophys., 2008, 482, 179.

62 R. L. Pulliam, B. A. McGuire and A. J. Remijan, Astrophys. J., 2012, 751, 1.

63 G. A. Blake, C. R. Masson, T. G. Phillips and E. C. Sutton, Astrophys. J., Suppl. Ser., 1986, 60, 357.

64 G. Pineau des Forets, E. Roueff and D. R. Flower, Mon. Not. R. Astron. Soc., 1990, 244, 668.

65 L. M. Ziurys, A. J. Apponi, J. M. Hollis and L. E. Snyder, Astrophys. J., Lett., 1994, 436, L181. 